\title{
Model for solid oxide fuel cell cathodes prepared by infiltration
}

\author{
Alfred Junio Samson ${ }^{\mathrm{a}, \mathrm{b}, \mathrm{e}}$, Martin Søgaard ${ }^{\mathrm{a}, \mathrm{c}, \mathrm{f}}$, and Peter Vang Hendriksen ${ }^{\mathrm{a}, \mathrm{d}}$
}

\begin{abstract}
A 1-dimensional model of a cathode has been developed in order to understand and predict the performance of cathodes prepared by infiltration of $\mathrm{La}_{0.6} \mathrm{Sr}_{0.4} \mathrm{Co}_{1.05} \mathrm{O}_{3-\delta}$ (LSC) into porous backbones of $\mathrm{Ce}_{0.9} \mathrm{Gd}_{0.1} \mathrm{O}_{1.95}(\mathrm{CGO})$. The model accounts for the mixed ionic and electronic conductivity of LSC, ionic conductivity of $\mathrm{CGO}$, gas transport in the porous cathode, and the oxygen reduction reaction at the surface of percolated LSC. Geometrical variations are applied to reflect a changing microstructure of LSC under varying firing temperatures. Using microstructural parameters obtained from detailed scanning electron microscopy and simulations of the measured polarization resistances, an expression for the area specific resistance $\left(r_{\mathrm{p}}\right)$ associated with the oxygen exchange on the surface of the infiltrated LSC particles was extracted and compared with literature values. A series of microstructural parameter variations are presented and discussed with the aim of presenting specific guidelines for optimizing the microstructure of cathodes prepared by infiltration.
\end{abstract}

Keywords: modeling, SOFC cathode, infiltration, mixed ionic and electronic conductor, nanoparticles 


\section{Introduction}

A key goal for the research in solid oxide fuel cells (SOFCs) is a lowering of the operating temperature to around $500-750^{\circ} \mathrm{C}[1]$, as this will greatly enhance the possibility for SOFC commercialization. Low operating temperature allows the use of cheap ferritic steel supports and interconnects instead of the more common yet comparatively more expensive Ni-based composite supports [2] and $\mathrm{LaCrO}_{3^{-}}$ based or specialty steel interconnects [3]. In addition, the long term stability of SOFCs is expected to be enhanced with reduced temperature of operation. Several degradation mechanisms are encountered under long term operation at high temperature, such as interfacial diffusion between electrode and electrolyte [4], gradual sintering of the electrode [5], Cr evaporation from the interconnect material and poisoning of the cathode [6], and $\mathrm{Sr}$ migration leading to the formation of undesired Sr-related reaction products $[7,8]$. These problems can be minimized with a reduction of the operating temperature. However, the electrochemical performance of the fuel cell electrodes decreases with decreasing temperature. Commonly used electrode materials, such as Sr-doped lanthanum manganite (LSM) and $\mathrm{Ni} /$ yttria stabilized zirconia (YSZ) composites prepared by conventional ceramic processing, do not have a sufficiently high performance at lower temperatures $\left(<650^{\circ} \mathrm{C}\right)$. Thus, it is necessary that new electrode materials with improved electrochemical performance are introduced and/or improved structures of the electrodes are employed. Essential to this search and development is the understanding on how various processes and parameters in electrode development affect the electrochemical performance of SOFC electrodes.

Porous composite electrodes are commonly used in solid oxide fuel cells as the triple phase boundary (TPB) is enhanced and the zone where the electrochemical reactions takes place is extended from the electrolyte. In the case of cathodes, it has been demonstrated that the area specific polarization 
resistance, $R_{\mathrm{p}}$, of a lanthanum strontium manganite (LSM) - yttria stabilized zirconia (YSZ) composite cathode is significantly lower than that of a cathode containing LSM only $[9,10]$. In recent years, it has been demonstrated that significant improvements in cathode performance can be achieved by using composites based on doped ceria, which possesses higher ionic conductivity than YSZ at low temperatures, and a mixed ionic and electronic conducting (MIEC) electrocatalyst material (in contrast to LSM being a predominantly electronic conductor) [11-19]. This allows an extension of the oxygen reduction zone from a narrow band along the TPB to the entire surface of the MIEC due to its higher ionic conductivity [20,21]. Another strategy to obtain improved cathodes is the tuning of the microstructure in order to enlarge the surface area for oxygen reduction. A tuning might be in the form of formation of nanoparticulate electrocatalysts in the electrode. One of the methods to obtain nanoparticulate electrocatalysts is the so-called infiltration or impregnation method [22-25]. The infiltrated nano-sized electrocatalysts have very large surface area and consequently, enhanced surface area for the oxygen exchange reaction. Indeed, exceptional performances, much better than their conventionally prepared counterparts, have been achieved by infiltrating MIEC electrocatalysts into CGO or YSZ backbones [22,26-31].

Like any other component development, developing cathodes is a costly and time-consuming process. Moreover, the factors and processes which affect their electrochemical performance are not fully understood. Mathematical models are highly useful to predict the performance of electrodes from material properties and microstructure. Combined with reliable experimental data, modeling can be a powerful technique, as it allows one to perform full parametric variations including those which are impractical for experiments. 
A considerable number of models that focus on porous composite electrodes for solid oxide fuel cells are already available in literature. Using simple electrode geometries, Kenjo et al. [32] and Tanner et al. [33] were able to predict the performance of porous composite cathodes with changing parameters and provide analytical expressions of the potential distribution in the composite electrode. Although insightful, these simplified models fail to address percolation in real composite cathodes and the effect of porosity on the gas diffusion. The percolation aspects have since then been addressed by several groups. Microstructural models which consider random packing, percolation limits, and triple phase boundary lengths of two types of spherical particles, typically LSM and YSZ, are common [34-37]. Most of these models also consider the gas transport in the pore structure of the composite electrode. These models generally recommend a small particle size for the electrocatalyst in order to increase the surface area or the triple phase boundary length, thus pointing to the use of nanoparticles in electrodes.

In the case of infiltrated SOFC cathodes, several modeling studies based on simple geometries have also been developed. Bidrawn et al. [38] extended the work of Tanner et al. [33] to investigate rate limiting cases (oxygen ion diffusion through the infiltrate film or reactive adsorption of $\mathrm{O}_{2}$ at the infiltrate surface) in a dense electrocatalyst coating in SOFC cathodes prepared by infiltration. Although the model captures the essential features of adsorption and diffusion of oxygen into the infiltrate material, the applicability on infiltrated cathodes is limited to those only forming a dense thin film coating on the backbone. Consideration of the gas diffusion in the porous structure was also neglected. Using a simple surface resistance (SR) model, Shah et al. [39] were able to model and predict the $R_{\mathrm{p}}$ of an $\mathrm{La}_{0.6} \mathrm{Sr}_{0.4} \mathrm{Co}_{0.2} \mathrm{Fe}_{0.8} \mathrm{O}_{3-\delta}$ - infiltrated $\mathrm{Ce}_{0.9} \mathrm{Gd}_{0.1} \mathrm{O}_{1.95}$ (LSCF/CGO) cathode where the surface exchange kinetics is the main limitation to the cathode performance. The calculated polarization resistances were within $40 \%$ of reported values despite having only the LSCF area specific 
resistance and the total LSCF surface area as inputs. However, the model overlooks the ionic and electronic conductivity limitations of the constituent phases. Further, the gas transport was not considered.

In this study, we address the geometrical and material property aspects that affect the performance of infiltrated cathodes. The developed model is an extended version of the 1-dimensional microstructural model including gas diffusion proposed by Nam and Jeon [34] and Søgaard et al. [40] which were previously used for ionic conductor (IC)/electronic conductor or mixed ionic and electronic conductor (MIEC) composite cathodes prepared by conventional means. The present model takes into account the IC backbone with a modified description of the geometrical characteristics of the infiltrated MIEC material, which is distributed as a thin film with hemispherical caps (referred to hereafter as thin coat model). The gas transport in the porous structure is also taken into account by using the dusty gas model. The effective ionic conductivities are calculated from the geometrical characteristics of the microstructure and the ionic conductivities of the constituent phases. The MIEC that is considered in this study is $\mathrm{La}_{0.6} \underline{\mathrm{Sr}}_{0.4} \mathrm{CoO}_{3-\delta}$ (LSC). LSC has been used as a cathode in many studies [19,27, 29-31]. The work is divided in several parts. In the first part, a conventional $\mathrm{La}_{0.6} \mathrm{Sr}_{0.4} \mathrm{CoO}_{3-\delta} / \mathrm{Ce}_{0.9} \mathrm{Gd}_{0.1} \mathrm{O}_{1.95}$ (LSC/CGO) composite cathode is analyzed using the binary sphere model [40] to extract an expression for the resistance associated with oxygen reduction at the LSC surface, $r_{\mathrm{p}}$. The derived expression is then compared to values from literature, where it is possible to deduce the value using various techniques such as ${ }^{16} \mathrm{O} /{ }^{18} \mathrm{O}$ isotope exchange experiments [41,42], electrical conductivity relaxation [43-45], electrolyte probe method [46] or polarization measurements on thin dense films [47]. In the second part, the expression for $r_{\mathrm{p}}$ is used as input to model the LSC infiltrated CGO backbone electrodes of the type described in Ref. [31], obtaining an expression for the total area specific 
polarization resistance of the electrode, $R_{\mathrm{p}}$, which is then compared to experimentally determined values of $R_{\mathrm{p}}$. In the last part, the thin coat model is used to perform parameter variations with the goal of designing a high performance cathode.

\section{Theory}

The theory behind the model is based on random packing of spheres consisting of electronic or MIEC and IC particles and has already been described by Nam and Jeon [34] and Søgaard et al. [40]. A short summary of this model and the extensions made is given here. It is important at this point to make a distinction between the two composite systems that are modeled here. The LSC/CGO composite cathode prepared by conventional means (screen-printing) will be referred to as conventional composite cathode while the LSC infiltrated-CGO cathode will be referred to as infiltrated cathode. The infiltrated cathodes considered in this study are those with the "LSC" infiltrate fired at 600 and $900{ }^{\circ} \mathrm{C}$ as described in our previous study [31] to highlight the difference in microstructure. It should be mentioned that the "LSC" infiltrate is composed of several phases [31] even at the firing temperature of $900{ }^{\circ} \mathrm{C}$ and it is very difficult to ascertain particles from each of the phases. It is assumed here that the particles are homogenous with properties that can be ascribed to a single "LSC" phase. The infiltrate will hereafter be called "LSC", even though it is composed of several phases. We have reported [31] that the firing temperature of $600{ }^{\circ} \mathrm{C}$ results in the lowest polarization resistances even though it appears that the amount of secondary phases particularly $\mathrm{SrCO}_{3}$ is largest at this temperature based on high temperature XRD data. Figs. 1a and 1b show scanning electron micrographs of a fracture and polished cross sections of a conventional LSC/CGO composite cathode, respectively. Figs. 1c and 1d show scanning electron micrographs of a fracture and polished cross sections, respectively, for an infiltrated cathode, where the infiltrate is LSC (fired at $600^{\circ} \mathrm{C}$ ), and the backbone is CGO. Figs. 1e and 1f show identical samples but after heat treatment at $900^{\circ} \mathrm{C}$. It is clear from the SEM micrographs that 
the nanoscale size of the LSC electrocatalyst in the infiltrated cathode provides a much higher surface area for oxygen surface exchange than the conventional composite cathode. Further, it appears that the LSC in the infiltrated cathode coats the CGO backbone. It is assumed in both composite systems that the two materials, LSC and CGO, have no interaction in the sense that the presence of CGO does not change the electrical/electrochemical properties of LSC and vice versa.

The corresponding illustrations of the model structures for both conventional composite and infiltrated cathodes are shown in Fig. 2. Fig 2a shows the schematic of the conventional composite cathode represented as random packing of spheres. Fig. $2 b$ shows the geometry of contact, defined by the contact angle $\left(\theta_{\mathrm{c}}\right)$ between two spheres with diameters $d_{\mathrm{IC}}$ and $d_{\mathrm{MIEC}}$. The two spheres represent the particles of the ionic conducting (IC) phase and the mixed ionic and electronic conducting (MIEC) phase in contact. Relevant microstructural parameters such as percolation probability, pore size, and surface area of percolated electrocatalysts are estimated using particle coordination number and percolation theory [48-50]. Depending on the volume fraction, the particle size characteristic for each phase, etc., the individual phases may form partial (presence of percolated clusters) or complete percolation. Fig. 2c shows a schematic for an infiltrated cathode. Unlike in the case of the conventional composite cathode, the IC phase forms complete percolation. In the case of the MIEC phase, it is clear from Fig. 1 that the microstructure may not be represented simply as an assembly of randomly positioned spheres. Instead, the MIEC can be better visualized as a corrugated coating on the IC particles. Fig. 2d simplifies this observed feature by representing the MIEC as a thin coating with attached spheres or hemispheres. One could infer, from this representation that the volume fraction of the MIEC that is needed to establish complete percolation can be much lower than in the case of the conventional composite cathode. This can be easily appreciated by the following simple geometrical 
consideration. Consider two spheres, an IC and a MIEC of equal diameters, $d_{\mathrm{IC}}=d_{\mathrm{MIEC}}=500 \mathrm{~nm}$, enclosed in a fixed rectangular box. The volume fraction is $50 \mathrm{vol} \%$ for each of the two phases. In an infiltrated cathode with $d_{\mathrm{IC}}=500 \mathrm{~nm}$ and MIEC coating with thickness, $t_{\text {coat }}=10 \mathrm{~nm}$, the volume fraction of the percolated MIEC coating is only $5.5 \mathrm{vol} \%$. The volume fraction of the MIEC coating would change with the IC particle radius and thickness of the coating, but the resulting vol \% of MIEC is, in realistic cases, always significantly lower than that of a conventional cathode. Indeed, there are experimental evidences that the infiltrated electrocatalyst material is still well connected even at loadings well below those necessary for percolation in random media [38,39,51]. In practice, the amount of MIEC can be increased to increase the available surface area for oxygen reduction. The increase in surface area is mainly due to the formation of nanoparticles protruding out from the dense MIEC layer around the IC particles. The resulting microstructure of the infiltrated MIEC will also depend on the infiltrate or backbone material and processing conditions such as the firing temperature but in general it can be described by the geometry shown in Fig. 2c. This peculiar configuration of the electrocatalyst particles therefore invalidates the direct use of percolation theory in an infiltrated cathode.

The geometrical description as shown in Fig. $2 \mathrm{c}$ and $2 \mathrm{~d}$ are adopted for the modeling of the infiltrated cathodes. The infiltrated electrocatalyst is characterized by a thickness, $t_{\text {coat }}$, on the ionic conducting backbone. As seen in the SEM investigations, LSC particles partly form spherical caps with height, $h$, protruding from the coating (called $N$ particles). The very large size difference between the CGO particles and the LSC particles makes the spherical cap assumption adequate for modeling the infiltrated cathode. A variation of the microstructure of the infiltrated cathode is also shown in Fig. 2d. In this case, particles of LSC are attached to the coating (called $M$ particles). This microstructure is 
commonly seen in cases of infiltrated cathodes with increased amount of electrocatalyst. Apparently, these particles provide additional surface area for oxygen exchange. The schematics in Fig. 2 serve as frameworks for the microstructure of the modeled cathodes.

The model formulation is divided into two parts. The first part deals with the composite cathode and follows the formulation described by Søgaard et al. [40]. The second part presents an extended geometrical formulation of the random packed spheres model to accommodate the microstructure of the infiltrated cathode. In both parts, the derivation of the microstructural parameters is presented first. The goal is to derive expressions for the surface area of the percolated part of the MIEC, the effective ionic conductivities of the MIEC and the IC phase, and the pore size which is used for gas transport calculations. This is followed by the mathematical formulation of diffusion through the porous structure. The last part in both cases describes the governing equations for the flow of mass and charged species in the cathode and the numerical procedures.

\subsection{Binary sphere model}

The cathode is modeled as a random packing system made up of mixed ionic and electronic conducting (MIEC) particles and ionic conducting (IC) particles with interstitial pores for transport of gas species. The number fraction of MIEC particles, $n_{\mathrm{MIEC}}$, is determined as [49]

$$
n_{M I E C}=\frac{\alpha^{3} \phi_{M I E C}}{1-\phi_{M I E C}+\alpha^{3} \phi_{M I E C}}
$$

where $\alpha$ is the ratio between the diameters of IC to MIEC particles $\alpha=d_{\mathrm{IC}} / d_{\mathrm{MIEC}}$ and $\phi_{\mathrm{MIEC}}$ is the volume fraction of the MIEC phase (solid volume fraction). The number fraction of the IC particles, 
$n_{\mathrm{IC}}$, can be found as $n_{\mathrm{MIEC}}=1-n_{\mathrm{IC}}$ and similarly $\phi_{\mathrm{MIEC}}=1-\phi_{\mathrm{IC}}$. The average total coordination number for MIEC particles is [49]

$$
Z_{M I E C}=3+\frac{Z-3}{n_{M I E C}+\left(1-n_{M I E C}\right) \alpha^{2}}
$$

and that for IC particles is

$$
Z_{I C}=3+\frac{Z-3}{n_{M I E C}+\left(1-n_{M I E C}\right) \alpha^{2}}
$$

where $Z$ is 6 for the binary random packing of spheres. The coordination number between an $i$-phase particle and a $j$-phase particle, $Z_{\mathrm{i}-\mathrm{j}}$, can be calculated as [49]

$$
Z_{i-j}=n_{i} \frac{Z_{i} Z_{j}}{Z}
$$

Suzuki and Oshima [48] proposed the expression to calculate the probability of an $i$-phase belonging to a percolated network of the same phase as

$$
P_{i}=\left[1-\left(\frac{4.236-Z_{i i}}{2.472}\right)^{2.5}\right]^{0.4}
$$

which has zero probability at the percolation threshold $\left(Z_{\mathrm{ii}} \leq 1.764\right)$. Conversely, $P_{\mathrm{i}}=1$ if $Z_{\mathrm{ii}} \geq 4.236$.

The effective conductivity of the $i$-phase, $\sigma_{i}^{\text {eff }}$, can be approximated as [34]

$$
\sigma_{i}^{e f f}=\sigma_{i}^{0}\left((1-\varepsilon) \phi_{i} P_{i}\right)^{m}
$$

where $\sigma_{i}^{0}$ is the bulk conductivity of phase $i, \varepsilon$ is the porosity of the electrode, $\phi_{\mathrm{i}}$ is the solid volume fraction of phase $i$, and $P_{\mathrm{i}}$ is the percolation probability. The exponent $m$ is called the Bruggeman factor and accounts for tortuous conduction pathways and is typically assumed to be $1.5[34,52]$. 
Essential to the estimation of the polarization resistance is the surface area of the percolated part of the MIEC. The surface area of the percolated MIEC phase per unit volume, $A_{M I E C}^{S p}$, can be calculated as

$$
A_{M I E C}^{s p}=\frac{\pi d_{M I E C}^{2}}{2}\left(2-Z_{M I E C}\left(1-\cos \left(\frac{\theta_{c}}{2}\right)\right)\right) n_{M I E C} P_{M I E C} N_{t}
$$

where $N_{\mathrm{t}}\left(\# / \mathrm{m}^{3}\right)$ is the number density of all particles given as

$$
N_{t}=\frac{1-\varepsilon}{\left(\frac{\pi}{6}\right) d_{M I E C}^{3}\left(n_{M I E C}+\left(1-n_{M I E C}\right) \alpha^{3}\right)}
$$

In Equation (7), $\theta_{\mathrm{c}}$ is the contact angle between MIEC and IC particles. A contact angle of $30^{\circ}$ is usually assumed $[34,35,37,40]$ as this represents well the physical situation after sintering of SOFC electrodes. However, in the case of the LSC/CGO composite considered in this study, there is a very good connectivity between CGO and LSC. It can readily be seen in Fig. 1a and 1b that the contact angle is much greater than $30^{\circ}$, most probably in the range $60-80^{\circ}$. In the study, the contact angle is set at $70^{\circ}$. The pore diameter, $d_{\mathrm{p}}$, for the gas transport calculations, is set equal to the hydraulic diameter, $d_{\mathrm{h}}$, which is expressed as

$$
d_{h}=\frac{4}{A_{0}} \frac{\varepsilon}{1-\varepsilon}
$$

where $A_{0}$ is the specific surface area based on the solid volume expressed as

$$
A_{0}=\left(\frac{6}{d_{M I E C}}\right) \frac{n_{M I E C}+\left(1-n_{M I E C}\right) \alpha^{2}}{n_{M I E C}+\left(1-n_{M I E C}\right) \alpha^{3}}
$$

The expressions used for the bulk ionic conductivities of the MIEC phase (LSC [53]) and the IC phase (CGO [54]) are listed in Table 1 while the microstructural parameters used in the model of conventional composite cathode are listed in Table 2. Jørgensen et al. [55] have already performed scanning electron microscopy and focused ion beam (FIB) tomography on the sample. The estimated 
area of the LSC available for the oxygen exchange reaction was a $=8.33 \times 10^{5} \mathrm{~m}^{2} \mathrm{~m}^{-3}$. To be able to arrive at this value using equation (7), the diameter of the LSC and CGO has to be ca. $1.3 \mu \mathrm{m}$, as set in Table 2. This diameter appears fairly consistent with the grain features in the SEM micrograph in Fig. 1b. The volume fractions of LSC and CGO are known from the ink preparation. The electronic conductivity of LSC is fixed at $2 \times 10^{5} \mathrm{~S} \mathrm{~m}^{-1}$.

In the modeling, the cathode is divided into segments [40,56] as shown schematically in Fig. 3 and the microstructural parameters discussed above are specified individually in each of these segments. Fig. 3 will be discussed in more detail when describing the governing equations. The model only considers a single composite electrode with a total thickness $L_{\mathrm{C}}$ divided into $i_{\max }$ elements. The partial pressures ( $p \mathrm{O}_{2}$ (gas), $p \mathrm{~N}_{2}$ (gas)) outside of this cathode structure is constant. The modeling involves solving the transport equations for gaseous oxygen, oxide ions and electrons under the requirement of conservation of mass and charge. The expressions in Fig. 3 are described in the succeeding paragraphs.

Fig. 4 shows the equivalent circuit showing the resistances associated with the processes (surface exchange and transport of species) in each of the segments for the schematic shown in Fig. 3. The transport path of the species can be represented as rails where the $\mathrm{O}^{2-}$ rail is separated from the electron and gas phase rail by the surface exchange process represented by $r_{\mathrm{p}, \mathrm{MIEC}}$.

The calculation of the diffusion through the porous structure uses the dusty-gas model $[57,58]$ and the procedure follows that of Nam and Jeon [34] and similarly, that of Søgaard et al. [40]. The molar fluxes of oxygen, $J_{\mathrm{O} 2}(i-1)\left(\mathrm{mol} \mathrm{m}^{-2} \mathrm{~s}^{-1}\right)$, and nitrogen, $J_{\mathrm{N} 2}(i-1)$, from segment $(i-1)$ to segment $(i)$, which are 
separated by the distance $\Delta \mathrm{x}_{(i-1)-(i)}$ as shown in Fig. 3 in the gas phase component, are calculated using the equations $[34,40]$

$$
\begin{aligned}
& J_{O_{2}}(i-1)=\frac{1}{R T}\left[\left(k_{1}+k_{2} \frac{p_{O_{2}}(i-1)+p_{O_{2}}(i)}{2}\right) \frac{p_{O_{2}}(i-1)+p_{O_{2}}(i)}{\Delta x_{(i-1)-(i)}}+k_{2} \frac{p_{O_{2}}(i-1)+p_{O_{2}}(i)}{2} \frac{p_{N_{2}}(i-1)+p_{N_{2}}(i)}{\Delta x_{(i-1)-(i)}}\right] \\
& J_{N_{2}}(i-1)=\frac{1}{R T}\left[\left(k_{3}+k_{4} \frac{p_{N_{2}}(i-1)+p_{N_{2}}(i)}{2}\right) \frac{p_{N_{2}}(i-1)+p_{N_{2}}(i)}{\Delta x_{(i-1)-(i)}}+k_{4} \frac{p_{N_{2}}(i-1)+p_{N_{2}}(i)}{2} \frac{p_{O_{2}}(i-1)+p_{O_{2}}(i)}{\Delta x_{(i-1)-(i)}}\right]
\end{aligned}
$$

It is important to note that in the steady state solution, the net molar flux of nitrogen between segments is zero as nitrogen is neither consumed nor produced. The constants, $k_{1}-k_{4}$, in Equations (11) and (12) are given as

$$
\begin{gathered}
k_{1}=\frac{D_{O_{2}-N_{2}}^{e f f} D_{O_{2}, K}^{\text {eff }}}{D_{O_{2}-N_{2}}^{e f f}+D_{O_{2}-N_{2}, K}^{e f f}} \\
k_{2}=k_{4}=\frac{1}{p_{O_{2}}+p_{N_{2}}} \frac{D_{O_{2}, K}^{e f f} D_{N_{2}, K}^{e f f}}{D_{O_{2}-N_{2}}^{e f f}+D_{O_{2}-N_{2}, K}^{e f f}}+\frac{\varepsilon^{3}}{k_{K}(1-\varepsilon)^{2} A_{0}^{2} \mu_{O_{2}-N_{2}}} \\
k_{3}=\frac{D_{O_{2}-N_{2}}^{e f f} D_{N_{2}, K}^{e f f}}{D_{O_{2}-N_{2}}^{e f f}+D_{O_{2}-N_{2}, K}^{e f f}}
\end{gathered}
$$

where $k_{\kappa}$ is the Kozeny constant and is around 5 for a porous media made of spherical particles [34]. The average viscosity of the gases, $\mu_{O_{2}-N_{2}}$, is given as $\mu_{O_{2}-N_{2}}=x_{O_{2}} \mu_{O_{2}}+x_{N_{2}} \mu_{N_{2}}$, where $x_{O_{2}}$ and $x_{N_{2}}$ are the molar fractions of oxygen and nitrogen in the gas phase, respectively and $\mu_{\mathrm{O}_{2}}$ and $\mu_{N_{2}}$ are the viscosities of oxygen and nitrogen, respectively. The effective binary diffusion, $D_{\mathrm{O}_{2}-N_{2}}^{\text {eff }}$, is calculated as $D_{O_{2}-N_{2}}^{\text {eff }}=\varepsilon / \tau D_{O_{2}-N_{2}}$. The tortuosity, $\tau$, is set to 3 as this typically represents porous electrodes of SOFCs [59]. The binary diffusion coefficient for oxygen and nitrogen, $D_{O_{2}-N_{2}}\left(\mathrm{~m}^{2} / \mathrm{s}\right)$, is obtained from [60] 


$$
D_{O_{2}-N_{2}}=\frac{0.0143 T^{1.75}}{p\left(1000 M_{O_{2}-N_{2}}\right)^{1 / 2}\left[{V_{O_{2}}}^{1 / 3}+{V_{N_{2}}}^{1 / 3}\right]^{2}}
$$

where $T(\mathrm{~K})$ is the absolute temperature, $p(\mathrm{~Pa})$ is the total pressure and $M_{\mathrm{O}_{2}-N_{2}}$ is the average molecular mass defined as $M_{O_{2}-N_{2}}=2\left(1 / M_{O_{2}}+1 / M_{N_{2}}\right)^{-1}$ where $M_{O_{2}}$ and $M_{N_{2}}\left(\mathrm{~kg} \mathrm{~mol}^{-1}\right)$ are the molecular weights of oxygen and nitrogen, respectively. $V_{\mathrm{O}_{2}}$ and $V_{\mathrm{N}_{2}}$ are the diffusion volume for oxygen and nitrogen, respectively. The values, $V_{O_{2}}=16.3$ and $V_{N_{2}}=18.5$ are used according to the recommendation of Todd and Young [61]. At $600^{\circ} \mathrm{C}$, the binary diffusion coefficient is $1.35 \times 10^{-4} \mathrm{~m}^{2}$ $\mathrm{s}^{-1}$.

The mixture Knudsen diffusion coefficient, $D_{O_{2}-N_{2}, K}^{e f f}$, in equations (13)-(15) is defined as $D_{O_{2}-N_{2}, K}^{e f f}=$ $x_{O_{2}} D_{N_{2}, K}^{e f f}+x_{N_{2}} D_{O_{2}, K}^{e f f}$, where $D_{i, K}^{e f f}$ for each species is defined as [34]:

$$
D_{i, K}^{e f f}=\frac{\varepsilon}{\tau} \frac{97}{2} d_{p} \sqrt{\frac{T}{1000 M_{i}}}
$$

The Knudsen diffusion is significant when the pore size becomes comparable to the mean free path of a gas molecule. In this case, an additional mass transport resistance has to be taken into account from the collision between the gas molecules and the solid structure [62]. A typical value of mixture Knudsen diffusion coefficient for $\mathrm{O}_{2}$ and $\mathrm{N}_{2}$ using the parameters for the infiltrated cathode considered in this study is $6.71 \times 10^{-6} \mathrm{~m}^{2} \mathrm{~s}^{-1}$ at $600^{\circ} \mathrm{C}$.

The calculation of the total polarization resistance, $R_{\mathrm{p}}$, involves solving a system of equations derived from considerations of charge and mass transfer conservation. For electrons and oxygen ions, the conservation equations are stated as 


$$
\begin{gathered}
-\sigma_{e l, M I E C}^{e f f} \frac{d \eta_{e l}}{d x}=-A_{M I E C}^{s p} i_{M I E C} \\
-\sigma_{i o, I C}^{e f f} \frac{d \eta_{i o}}{d x}=A_{M I E C}^{s p} i_{M I E C}
\end{gathered}
$$

where $\sigma_{e l, M I E C}^{e f f}$ and $\sigma_{i o, I C}^{e f f}$ are the effective electronic conductivity in the MIEC phase and the effective ionic conductivity in the IC phase, respectively and $\eta_{e l}$ and $\eta_{i o}$ are the electric potentials in the electronic (MIEC) and ionic phase, respectively. $i_{M I E C}\left(\mathrm{C} \mathrm{m}^{-2} \mathrm{~s}^{-1}\right)$ is the current generated through the electrode reaction per unit area. $A_{M I E C}^{S p} i_{M I E C}$ is a charge transfer term that reflects the amount of current generated per unit volume and time $\left(\mathrm{C} \mathrm{m}^{-3} \mathrm{~s}^{-1}\right)$. The terms in Equations (18) and (19) are further elaborated in the following paragraphs.

As also shown schematically in Fig. 3, the reduction of gaseous oxygen at segment ( $i$ ) generates oxide ions that will either be transported to the electrolyte in the MIEC phase or transferred to the IC phase. The conservation of oxide ions in the MIEC phase requires that the flux of oxide ions into segment $(i)$, $J_{O^{2-}, M I E C}(i)$, is equal to the sum of the flux of oxide ions coming from segment $(i-1), J_{O^{2-},{ }_{M I E C}}(i-$ 1), and the total flux of oxide ions that is generated in the segment $(i)$ by reduction of gaseous oxygen, $J_{O^{2-}, \text { gas } \rightarrow M I E C}(i)$, minus the flux of the ions transferred from the MIEC phase to the IC phase, $J_{O^{2-}, M I E C \rightarrow I C}(i)$, in segment $(i)$ :

$$
J_{O^{2-}, M I E C}(i)=J_{O^{2-},{ }_{g a s} \rightarrow M I E C}(i)+J_{O^{2-}, M I E C}(i-1)-J_{O^{2-}, M I E C \rightarrow I C}(i)
$$

and similarly, for the conservation of oxide ions in the IC phase:

$$
J_{O^{2-}, I C}(i)=J_{O^{2-}, M I E C \rightarrow I C}(i)+J_{O^{2-}, I C}(i-1)
$$


where $J_{O^{2-}, I C}(i)$ and $J_{O^{2-}, I C}(i-1)$ are the flux of oxide ions in the $(i)$ and $(i-1)$ segments, respectively. Thus, the total flux of oxide ions into segment $(i)$ can be expressed as:

$$
\begin{aligned}
J_{O^{2-}}(i) & =J_{O^{2-}, M I E C}(i)+J_{O^{2-}, I C}(i) \\
& =J_{O^{2-}, \text { gas } \rightarrow M I E C}(i)+J_{O^{2-}, M I E C}(i-1)+J_{O^{2-}, I C}(i-1)
\end{aligned}
$$

It is assumed that the transport of oxide ions from the MIEC phase to the CGO phase (or vice versa) has no associated resistance. The flux of oxide ions that is generated in segment $(i)$ by the reduction of gaseous oxygen, $J_{O^{2-}, \text { gas } \rightarrow M I E C}(i)$, is related to the current density in the volume segment $(i), i_{M I E C}(i)$, by the equation

$$
J_{O^{2-}, \text { gas } \rightarrow M I E C}(i)=-\frac{1}{2 F} A_{M I E C}(i) i_{M I E C}(i)
$$

where $\mathrm{F}$ is the Faraday constant, $A_{M I E C}(i)$ is the active surface area of the percolated MIEC in the segment $(i)$ and can be expressed as $A_{M I E C}(i)=V(i) A_{M I E C}^{s p}(i)$ where $V(i)$ is the volume in the segment and $A_{M I E C}^{S p}(i)$ is the volume specific surface area of the percolated MIEC in the segment $(i)$. $i_{M I E C}(i)$ can be expressed from the overpotential in the segment, $\eta(i)$, and the material specific polarization resistance in the segment, $r_{p, M I E C}(i)$ as

$$
i_{M I E C}(i)=\frac{\eta(i)}{r_{p, M I E C}(i)}
$$

The overpotential in segment $(i)$ is given by

$$
\eta(i)=\eta_{i o}(i)+\eta_{e l}(i)+\eta_{g a s}(i)
$$

where $\eta_{e l}$ and $\eta_{i o}$ are the electric potentials in the electronic (MIEC) and ionic phase, respectively, and $\eta_{g a s}$ is the gas concentration polarization. $\eta_{e l}$ in segment $(i)$ is calculated as:

$$
\eta_{e l}(i)=\eta_{e l}(i-1)+I_{e^{-}}(i-1) R_{e l}(i-1)
$$


where $I_{e^{-}}(i-1)$ is the electronic current transported from segment $(i-1)$ to segment $(i)$. The resistance associated with this transport, $R_{e l}(i-1)$, is given as

$$
R_{e l}(i-1)=\frac{\Delta x}{\sigma_{e l, M I E C}^{e f f} A_{C}}
$$

where $\Delta x$ is the distance between the middle of segment $(i)$ and segment $(i-1)$ and $A_{C}$ is the unit area of the cathode. The electric potential in the ionic phase, $\eta_{i o}$, is calculated the same way as (26):

$$
\eta_{i o}(i)=\eta_{i o}(i-1)+I_{i o}-(i-1) R_{i o}(i-1)
$$

where $I_{i o^{-}}(i-1)$ is the equivalent current associated with the transport of oxide ions from segment ( $i-1)$ to segment $(i) . R_{i o}(i-1)$ is the resistance associated with the transport of oxide ions in the said segments. $R_{\text {io }}$ is the equivalent resistance associated with the transport of oxide ions in both the IC and MIEC phases placed in parallel. It is important to note that due to the assumption of zero resistance in the transfer of oxide ions between the IC and MIEC phase, the probability of percolation, $P_{I C}$, in the calculation of the effective ionic conductivity using Equation (5) is set to unity. The gas concentration polarization in segment $i$ is given by

$$
\eta_{g a s}(i)=\frac{R T}{4 F} \ln \left(\frac{p_{O_{2}}(i)}{p_{O_{2}}(g a s)}\right)
$$

where $p_{\mathrm{O}_{2}}(\mathrm{gas})$ is the oxygen partial pressure outside the electrode structure. For SOFC cathode operation, $p_{\mathrm{O}_{2}}(i)<p_{\mathrm{O}_{2}}$ (gas), wherefore $\eta_{g a s}(i)$ is negative.

The numerical calculation starts by specifying the composition and microstructural inputs such as the volume fraction of components, particle sizes, porosity, tortousity, thickness of cathode, etc. The bulk conductivity of the IC and MIEC phases are also defined according to temperature. The cathode structure is divided into segments where the microstructural inputs are defined. The effective 
conductivities are then calculated using Equation (6) along with the specific surface area of the percolated MIEC, using Equation (7). Using these results, the resistance for the transport of electrons and oxide ions between segments are found. Before the iteration, the current that should pass through the electrolyte is specified. Iteration begins by guessing the overpotential in the segment which is closest to the electrode/gas interface. The current density in this segment is then calculated using Equation (24). The total current in the segment is then found and employed to calculate the electric potentials in the next segment using Equations (26) and (28). The calculated electric potentials would then be used to obtain the current in the segment. The procedure continues until the electrolyte is reached and a current through the electrolyte is determined. The iteration is followed by the estimation of the gas concentration polarization through the calculation the partial pressures in each of the segments using the flux Equations, (11) and (12). The whole iteration is repeated but the guessed overpotential now includes the gas concentration polarization. The procedure continues until convergence has been obtained. Typically, at least 100 segments are necessary to ensure accuracy of the solution $\left(1 \times 10^{-3} \Omega \mathrm{cm}^{2}\right.$ for $R_{\mathrm{p}}$ ). Block diagrams of the algorithm depicting various ways of obtaining information for both the binary sphere and the thin coat models are presented in Figures 5 and 6. Fig. 5 shows the algorithm for obtaining a best fit of $R_{\mathrm{p}}$ 's by determining optimized constants $c_{1}$ and $c_{2}$ for the expression $r_{p}=c_{1} \exp \left(\frac{c_{2}}{R T}\right)$. Note that parameters related to gas transport in the electrode are not included in the calculation. The reason is discussed further in the text. Figure 6 shows the algorithm for obtaining calculated $R_{\mathrm{p}}$ 's where the constants $c_{1} \underline{\text { and }} c_{2} \underline{\text { have been extracted through }}$ fitting from Fig. 5 or from literature. It is apparent from Fig. 6 that calculations related to surface exchange and ionic and electronic species are separate from the calculations related to gas transport. The resulting resistances can be added to extract the total polarization resistance. 


\subsection{Thin coat model}

The IC backbone is modeled from a random packing of spherical particles as outlined in the composite cathode case. However, in this case, the volume fraction of the IC and the probability of percolation are set to unity. The effective ionic conductivity of the IC phase is then reduced to

$$
\sigma_{i o, I C}^{e f f}=\sigma_{I C}^{0}(1-\varepsilon)^{1.5}
$$

where $\sigma_{i o, I C}^{0}$ is the bulk ionic conductivity of the IC phase. The calculation of the resistance associated with the transport of electrons follows the geometrical considerations illustrated in Fig. 2c. The resistance is assumed to be ohmic with electrons flowing through the coating only, which is approximated as a sheet with a cross sectional area, $A_{\text {coat }}$, expressed as

$$
A_{\text {coat }}=l_{\text {coat }} t_{\text {coat }}
$$

where $t_{\text {coat }}$ is the thickness of the coating and $l_{\text {coat }}$ is the length of the coating parallel to the CGO electrolyte as depicted schematically in Fig. 7a. The length of the coating is expressed as

$$
l_{\text {coat }}=\pi d_{I C, \text { coat }} \sin \left(\frac{\theta_{C}}{2}\right) N_{t} d_{I C, \text { coat }} n_{I C} P_{I C} A_{C}
$$

where $d_{I C, \text { coat }}$ is the diameter of the IC particle with additional coating $\left(d_{I C, \text { coat }}=d_{I C}+2 t_{\text {coat }}\right)$ and $A_{C}$ is the geometric area of the cathode. $P_{I C}$ and $n_{I C}$ are set to 1 . This equation is identical to the expression used to calculate the triple phase boundary length of the electronic particles in contact with an electrolyte [34]. It is easy to see that Equation (31) overestimates the actual cross-sectional area of the coating to a certain degree. For example, a thickness of $10 \%$ of the radius of the IC particle gives an overestimation error of about $4.8 \%$ compared to the exact area calculated by subtracting the area of the circle formed by cutting the IC sphere in half from the area of the circle of the IC sphere with the 
thickness added. The error drops considerably for thin coatings. Because of the very thin coatings considered here (i.e. $d_{I C} \gg t_{\text {coat }}$ or $r_{I C} \gg t_{\text {coat }} / 2$, where $r_{I C}$ is the radius of the IC particle) and since it is difficult to know exactly the diameters of spheres sliced in a segment to be able to calculate an exact cross sectional area, Equation (31) is found sufficient to estimate $A_{\text {coat }}$.

The resistance associated with transporting electrons in the MIEC from segment (i-1) to $(i)$ can be expressed as

$$
R_{e l, M I E C}(i-1)=\frac{\tau \Delta x}{A_{\text {coat }} \sigma_{e l, M I E C}^{0}}
$$

where $\tau$ is the tortousity of the IC phase and $\sigma_{e l, M I E C}^{0}$ is the bulk electronic conductivity of the MIEC phase. Similarly, the ionic resistance from segment (i-1) to $(i)$ in the MIEC phase can be expressed as

$$
R_{i o, M I E C}(i-1)=\frac{\tau \Delta x}{A_{\text {coat }} \sigma_{i o, M I E C}^{0}}
$$

where $\sigma_{i o, M I E C}^{0}$ is the bulk ionic conductivity of the MIEC phase. The calculation of the total ionic resistance is the same as that of the composite cathode case, where the IC and MIEC phase are placed in parallel only that Equation (34) is used for the MIEC phase. It is readily seen in Equation (33) that the thin coat model could not account for any loss of percolation as in the case of the binary sphere model. In actual electrodes, the coating may not be continuous throughout the whole cathode, thus the electronic path may be longer which increases the electronic resistance as defined in Equation (33). In theory, this contribution may be incorporated as a probability factor related to poor percolation. This is not defined in the present study. However, as will be seen in the discussion on the effect of the electronic conductivity of the infiltrate on $R_{\mathrm{p}}$, it appears that this factor is not particularly significant for cathodes containing sufficient amount of electrocatalysts with very high electronic conductivity. 
In the calculation of the surface area of the percolated MIEC and the pore diameter, the thickness, $t_{\text {coat }}$, of the coating and the spherical caps together with the attached spheres are also taken into account as shown in Fig. 2d. The surface area, $A_{I C-M I E C}^{\text {particle }}$, of one IC particle with coating can be expressed in terms of the specific surface area of the IC backbone with coating over the number density of the IC particles,

$$
A_{I C-M I E C}^{\text {particle }}=\frac{A_{I C-M I E C}}{N_{t, \text { inf }}}
$$

where $A_{I C-M I E C}$ is the specific surface area of the CGO backbone with the added coating given as

$$
A_{I C-M I E C}=\frac{\pi d_{i o, \text { coat }}^{2}}{2}\left(2-Z_{I C}\left(1-\cos \left(\frac{\theta_{c}}{2}\right)\right)\right) n_{I C} P_{I C} N_{t, \text { inf }}
$$

and where $N_{t, \text { inf }}$ is expressed as

$$
N_{t, i n f}=\frac{1-\varepsilon}{\left(\frac{\pi}{6}\right) d_{i c}^{3}}
$$

Since the only particles considered for the random packing are the IC particles, the following variables are set in Equation (34): $Z_{I C}=6, n_{I C}=1$, and $P_{I C}=1$. If the surface of one IC particle with coating is as shown in Fig. $\underline{7}$ b, the increase in surface area with respect to $A_{I C-M I E C}^{\text {particle }}$, referred to as the surface area factor, $s$, can be expressed as

$$
s=\frac{A_{I C-M I E C}^{\text {particle }}-N \pi a^{2}+N 2 \pi r h+M 4 \pi r^{2}}{A_{I C-M I E C}^{\text {particle }}}
$$

where $N$ is the number of MIEC spherical caps on one IC particle (with coating), $M$ is the number of spherical MIEC particles attached to the IC particle, $a$ is the base radius, $r$ is the radius of the spherical MIEC particle and $h$ is the spherical cap height. For a hemispherical cap that is assumed in this study ( $a$ $=r=h)$, Equation (38) reduces to 


$$
s=\frac{A_{I C-M I E C}^{\text {particle }}+N \pi r^{2}+M 4 \pi r^{2}}{A_{I C-M I E C}^{\text {particle }}}
$$

The maximum number of hemispherical caps that would fill the IC particle without overlapping is given by

$$
N_{\max }=\frac{A_{I C-M I E C}^{\text {particle }}}{4 r^{2}}
$$

The calculation of the pore diameter follows accordingly. The pore diameter, $d_{p, \text { inf }}$, in the infiltrated case is the same as Equation (9) but with $A_{0, \text { inf }}$ expressed as

$$
A_{0, \text { inf }}=\frac{6}{d_{i o, \text { coat }}}+2 N_{t, \text { inf }} N \pi r^{2}+4 N_{t, \text { inf }} M \pi r^{2}
$$

The calculation of the diffusion through the porous structure is identical to that of the composite cathode. Note that the porosity is also adjusted as the total volume of added hemispherical caps and spherical particles are added to the total volume of the electrode. The numerical procedure for the calculation of $R_{\mathrm{p}}$ is the same as the one outlined for the conventional composite cathode case.

The microstructural parameters used in modeling the infiltrated cathode are listed in Table 3. The radius of the LSC particles, $r_{\mathrm{LSC}}$, and number of LSC particles $(M$ or $N)$ attached per CGO particle are estimated directly from the SEM images.

\section{Results and Discussion}

\subsection{LSC/CGO conventional composite cathode}


In modeling the porous LSC/CGO composite cathode, the binary sphere model is used directly. Shown in Fig. $\underline{8}$ is the polarization resistance as a function of the reciprocal absolute temperature in air where the contribution originating from diffusion in a stagnant gas layer above the sample and the gas transport in the electrode have been subtracted for the LSC/CGO conventional composite cathode. To be able to subtract these contributions, it was necessary to identify them from the impedance spectra of the LSC/CGO cathode. The identification was performed by fitting an equivalent $R C$ circuit element to the low frequency arc in the impedance spectra that is sensitive to the change in oxygen partial pressures. Also shown in Fig. $\underline{8}$ is the best fit of the binary sphere model where the parameters listed in Table 1 and Table 2 have been used to generate the microstructure. The contribution originating from the gas transport in the electrode is excluded in the fitting. The diffusion in a stagnant gas layer above the sample and the gas transport in the electrode are usually difficult to separate. Since the model can only describe the gas transport in the porous cathode and not the stagnant gas layer above the sample, the gas transport in the porous cathode is excluded altogether in the extraction of $r_{\mathrm{p}}$.

The expression for the resistance associated with oxygen reduction of LSC is defined in the present study as

$$
r_{p}=c_{1} \exp \left(\frac{c_{2}}{R T}\right)
$$

From the fitting with the gas transport subtracted, $c_{1}$ and $c_{2}$ are found to be $5.47 \times 10^{-12} \Omega \mathrm{m}^{2}$ and $1.30 \mathrm{x}$ $10^{5} \mathrm{~J} \mathrm{~mol}^{-1}$, respectively. The experimental data and the best fit are shown in Fig. $\underline{8}$. 
It is important to note that the model can also accept as an input, the expression for $r_{\mathrm{p}}$. Also shown in Fig. $\underline{8}$ are the calculated $R_{\mathrm{p}}$ 's when the expression for $r_{\mathrm{p}}$ derived from the thin film measurements performed by Baumann et al. [63], a porous $\mu \mathrm{m}$-scaled cathode structure by Adler [64], conductivity relaxation measurements of an LSC pellet by Søgaard et al. [53], and the nanoscaled and nanoporous cathodes by Hayd et al. [65] are used. The work of Søgaard et al. can be considered as treatment of LSC in the "bulk" form as can be differentiated from the work of Baumann et al. and Hayd et al. which were treatments of LSC as nano-sized thin film. The $r_{\mathrm{p}}$ values derived from Mortensen et al. [66] is also shown on Fig. $\underline{8}$. In the work of Mortensen et al., an analytical, 1-dimensional impedance model of a composite LSC/CGO cathode was derived. The model is a generalized model, encompassing both an ionic conductor and a MIEC of the treatment given by Adler, Lane, and Steele for a SOFC consisting solely of MIEC [20]. The same cathode which was analyzed in the Mortensen et al. is also analyzed in the present work. The calculated $R_{\mathrm{p}}$ 's derived when the $r_{\mathrm{p}}$ from the work of Adler [64] and Søgaard et al. [53] can be considered to be in very good agreement with the experimentally observed value, especially when considering the difference in the methods used for obtaining $r_{\mathrm{p}}$. Ideally, the calculated $R_{\mathrm{p}}$ values when $r_{\mathrm{p}}$ from Mortensen et al. is used, should be in perfect agreement with the measured data shown in Fig. $\underline{8}$ since the analyzed cathode is the same. The small discrepancy originates mainly from the fact that in the present work, the oxide ion conductivity of CGO is based on literature values whereas in the work of Mortensen et al., the ionic conductivity was also fitted in the form of an effective vacancy diffusion. In this case, the slightly higher $r_{\mathrm{p}}$ (slower oxygen surface exchange) determined in the present work, could indicate that the used effective ionic conductivity is slightly higher than that fitted by Mortensen et al. 
In contrast to very good agreement of the works above, the obtained $R_{\mathrm{p}}$ 's when the $r_{\mathrm{p}}$ values from the work of Baumann et al. [63] and Hayd et al. [65] were very different. A summary of the extracted activation energies and $R_{\mathrm{p}}$ 's is shown in Table 4 . The $R_{\mathrm{p}}$ 's at $750{ }^{\circ} \mathrm{C}$ derived using Baumann et al. values were ca. 14 times higher than the experimental value while that using Hayd et al. were ca. 8 times lower. It is most likely that the discrepancy is due to the difference in the surface exchange characteristics of the LSC in the composite cathode in the present study and that of the LSC thin film deposited by PLD (Baumann et al.) and that of the nanoscaled and nanoporous LSC cathode (Hayd et al.). The surface composition of the LSC thin film deposited by PLD could have been very different from that in the LSC/CGO composite. Kubicek et al. [67] have shown strong correlations between changes in electrode polarization resistance of oxygen reduction and surface composition. In the case of the nanoscaled LSC cathode, it was also discussed in the work of Hayd et al. that these particular cathodes have enhanced oxygen surface exchange properties compared to those of bulk LSC. The fair agreement of the generated $R_{\mathrm{p}}$ 's with the experimental value when the area specific resistance $\left(r_{\mathrm{p}}\right)$ was derived from literature measurements of bulk LSC verifies the soundness of the model.

\subsection{Infiltrated cathodes}

\subsubsection{Infiltrated cathode fired at $600{ }^{\circ} \mathrm{C}$}

Fig. $\underline{9}$ shows the experimental data of the infiltrated cathode fired at $T_{\max }=600{ }^{\circ} \mathrm{C}$ together with $R_{\mathrm{p}}{ }^{\prime} \mathrm{s}$ calculated using various $r_{\mathrm{p}}$ 's derived from literature as also described in section 3.1. The $r_{\mathrm{p}}$ obtained from fitting the LSC/CGO composite data in section 3.1 is also used. The model as described in section 2.2 for the infiltrated cathode is employed. It is important to consider that the "LSC" discussed here is multi-phased as shown in our previous work [31]. Thus, the surface exchange resistance extracted here 
is essentially that from a mixture of nanoparticulate electrocatalysts. The measured data lies within the range of calculated $R_{\mathrm{p}}$ 's if the $r_{\mathrm{p}}$ 's used are those derived from the treatments of micron-sized LSC such as from the work of Mortensen et al., Adler, and the LSC/CGO fit from the composite cathode in the present study. Considering that the experimentally observed value is slightly lower than the calculated value when $r_{\mathrm{p}}$ of the LSC/CGO fit and the Mortensen et al. work were used, especially at low temperatures $\left(<400{ }^{\circ} \mathrm{C}\right)$, it may be suggested that the performance of the LSC infiltrate is expected to be comparable to or better than an LSC/CGO conventional composite. This can be inferred from the fact that the calculated $R_{\mathrm{p}}$ when $r_{\mathrm{p}}$ of LSC/CGO is used could not realistically be made to reconcile with the experimentally observed values just by tweaking the microstructural parameters only. For example, to be able to get the calculated $R_{\mathrm{p}}$ equal to the experimentally observed value at $400{ }^{\circ} \mathrm{C}$, additional M particles $=200$ has to be added. This is clearly not the case in Fig. 1c. Similar to the case of the LSC/CGO composite, the generated $R_{\mathrm{p}}$ 's at $600{ }^{\circ} \mathrm{C}$ from the thin coat model using $r_{\mathrm{p}}$ 's from Baumann et al. overestimates the $R_{\mathrm{p}}$ by ca. 5 times and that from Hayd et al. underestimates $R_{\mathrm{p}}$ by 5 times. A summary of the extracted activation energies and $R_{\mathrm{p}}$ 's is shown in Table 4 . The findings suggest that: (1) the thin coat model is sound and the considerations in the model describes the actual cathode fairly well and (2) the LSC infiltrate behaves close to extrapolations from composites and bulk LSC evaluations even though it is non-single phase. The suggested possibility in our previous work [31] that the particular infiltrate has significantly improved area specific oxygen surface exchange due to the presence of various phases may not be entirely correct based on the analysis of the electrode results using the detailed microstructural model described in section 2.2.

\subsubsection{Infiltrated cathode fired at $900^{\circ} \mathrm{C}$}


Fig. 10 shows the experimental data of the infiltrated cathode fired at $T_{\max }=900{ }^{\circ} \mathrm{C}$ together with $R_{\mathrm{p}}{ }^{\prime} \mathrm{s}$ generated using various $r_{\mathrm{p}}$ 's derived from literature as also described in section 3.1 and 3.2.1. The $r_{\mathrm{p}}$ obtained from fitting the LSC/CGO composite in section 3.1 and from the fitting of the infiltrated cathode at $T_{\max }=600{ }^{\circ} \mathrm{C}$ are also used. The measured data lies closer to the calculated $R_{\mathrm{p}}$ 's when the $r_{\mathrm{p}}$ 's used are those derived from micron-sized LSC treatments (i.e. those from Mortensen et al., Adler, and the LSC/CGO fit from the composite cathode in the present study) and bulk LSC treatment (Søgaard et al.) than when the $r_{\mathrm{p}}$ 's used are from thin film and nanoscaled LSC measurements (Baumann et al. and Hayd et al.). Looking at comparisons with micron-sized and bulk LSC measurements only, it may be noticed that the $R_{\mathrm{p}}$ 's are mostly underestimated. This implies that the performance of the infiltrated LSC that is fired at $900{ }^{\circ} \mathrm{C}$ can be comparable or inferior to an LSC/CGO conventional composite. Compared to the same infiltrate but fired at $600{ }^{\circ} \mathrm{C}$, it appears that the surface exchange process is slower in the infiltrate fired at $T_{\max }=900{ }^{\circ} \mathrm{C}$. The $R_{\mathrm{p}}$ is underestimated when the $r_{\mathrm{p}}$ obtained at $T_{\max }=600{ }^{\circ} \mathrm{C}$ is used. Further, the $R_{\mathrm{p}}$ can only be adjusted to approach the experimentally observed value by setting the microstructural parameters to a case that is obviously not observed in the SEM micrographs (i.e., $\mathrm{N}=0, d_{\mathrm{CGO}}>300 \mathrm{~nm}$ ). The changes in the phases comprising the "LSC" infiltrate brought about by the increased firing has resulted to an inferior surface exchange property. A summary of the extracted activation energies and $R_{\mathrm{p}}$ 's is shown in Table 4 .

\subsection{Optimization of infiltrated cathodes}


A number of studies have already carried out parametric variations of composite cathodes consisting of IC and electronic/MIEC phases using the random sphere model with the goal of obtaining cathodes with optimized microstructure $[34,35,37,40,68]$. Here, we examine the physical properties essential to the infiltrated cathodes. In the previous discussions, the influence of gas transport in the infiltrated cathodes was not considered. In the following, the parametric variations include the gas transport in the electrode structure but not a stagnant gas layer. The variables of interest are varied while keeping the other structural parameters constant according to Table 3 in the following parametric studies.

\section{The effect of cathode thickness}

The effect of the thickness of the cathodes on $R_{\mathrm{p}}$ is shown in Fig. 11. Fig. 11a shows the effect of the thickness of the cathode on $R_{\mathrm{p}}$ at varying temperatures. Notable for all temperatures is the decrease in $R_{\mathrm{p}}$ when the thickness is increased from $\sim 1 \mu \mathrm{m}$ to several micrometers. This is due to an increasing surface area available for oxygen reduction. This also implies that the IC phase has sufficient ionic conductivity for the range of thickness considered to transport the oxide ions to the electrolyte. When the thickness of the cathode is further increased, an increase in $R_{\mathrm{p}}$ is seen especially at high temperatures $\left(>700{ }^{\circ} \mathrm{C}\right)$. The absolute increase is almost identical for all temperatures, but it is only clearly seen at higher temperatures because of the low $R_{\mathrm{p}}$. With an increase in thickness, the available surface area for oxygen reduction is increased, but the length for gas transport is also increased which contributes more to $R_{\mathrm{p}}$. Fig. $\underline{11 \mathrm{~b}}$ compares the $R_{\mathrm{p}}$ values at varying temperatures for selected cathode thicknesses. It is clear that the effect of cathode thickness is most significant at low temperatures. The difference in the relative values of $R_{\mathrm{p}}$ decreases with increasing temperatures as reflected in the decrease in activation energy in going from $1 \mu \mathrm{m}\left(109 \mathrm{~kJ} \mathrm{~mol}^{-1}\right)$ to $75 \mu \mathrm{m}\left(82 \mathrm{~kJ} \mathrm{~mol}^{-1}\right)$ thick indicating 


\section{The effect of electronic conductivity in the MIEC phase}

A related parameter that is very important, especially in infiltrated cathodes where the electrocatalysts are nanosized, is the electronic conductivity. This can be a concern because even though the bulk electronic conductivity is high, the cross sectional area defined by $A_{\text {coat }}$ in Equation (31) can be very low which still translates into high electronic resistance. Based on the calculated value for $l_{\text {coat }}$, it is calculated that the $A_{\text {coat }}$ is only $4 \%$ of that of the geometrical area of the cathode, $A_{\mathrm{C}}$, if $t_{\text {coat }}=5 \mathrm{~nm}$. Fig. 12a compares the calculated $R_{\mathrm{p}}$ 's obtained from hypothetical infiltrates with varying bulk electronic conductivities but the same bulk ionic conductivities and surface exchange properties. The scenario for a thinner infiltrate coating $(1 \mathrm{~nm})$ is also shown for comparison (Fig. 12b). The parameters in the case 
for LSC fired at $T_{\max }=900{ }^{\circ} \mathrm{C}$ are also used. The gas transport is not included in the calculation. The electronic conductivities, 19000 and $4000 \mathrm{~S} \mathrm{~m}^{-1}$, correspond to that for $\mathrm{Ca}_{3} \mathrm{Co}_{4} \mathrm{O}_{9+\delta}[69]$ and $\mathrm{Co}_{3} \mathrm{O}_{4}$ [70] at $900^{\circ} \mathrm{C}$, respectively. It can be observed from Fig. $\underline{12} \mathrm{~b}$ that by decreasing the electronic conductivity of the coating, the $R_{\mathrm{p}}$ increases. However, the increase is only significant at high temperatures $\left(>600^{\circ} \mathrm{C}\right)$ and at electronic conductivities significantly lower (100-fold) than the electronic conductivity of LSC. As most electrocatalyst used in SOFCs have electronic conductivities greater than $20000 \mathrm{~S} \mathrm{~m}^{-}$ ${ }^{1}$, their electronic conductivity would not significantly contribute to the polarization resistance. In the case of a thinner coating such as that shown in Fig. $\underline{12 \mathrm{~b}}$ for $1 \mathrm{~nm}$, the same trend as that for a $5 \mathrm{~nm}$ coating is seen, only that the increase in $R_{\mathrm{p}}$ is relatively greater with decreasing electronic conductivity. This result is expected considering the decrease in the cross sectional area for electron transport. To provide a specific range of values with other parameters fixed, the $R_{\mathrm{p}}$ at $900^{\circ} \mathrm{C}$ is doubled if $\sigma_{L S C, e l}$ / $\sigma_{M I E C, e l} \sim 130$ for $\left.t_{\text {coat }}=5 \mathrm{~nm}\right)$ and $\sigma_{L S C, e l} / \sigma_{M I E C, \text { el }} \sim 30$ for $t_{\text {coat }}=1 \mathrm{~nm}$ where $\sigma_{L S C, \text { el }}\left(2 \times 10^{5} \mathrm{~S} \mathrm{~m}^{-}\right.$ ${ }^{1}$ ) is the bulk electronic conductivity of LSC, and $\sigma_{M I E C, e l}$ is the electronic conductivity of potential infiltrate. As a comparison, for the same ratio $\sigma_{L S C, e l} / \sigma_{M I E C, e l}$, the $R_{\mathrm{p}}$ at $600^{\circ} \mathrm{C}$ is only increased by $6 \%$ for both coating thicknesses.

As already mentioned, the present model does not account for the increase in electronic resistance due to a loss of percolation. However, from Fig. 12a, it appears that this may not significantly affect the calculation in infiltrated cathodes where there is a high amount (>10 vol \% from the total electrode volume) of electrocatalysts that have high (> $5000 \mathrm{~S} \mathrm{~m}^{-1}$ ) electronic conductivity. It is evident that the loss of percolation may be considered as a decrease in electronic conductivity. 


\section{The effect of the surface area of the MIEC phase}

Fig. 13a illustrates how much the surface area of the LSC is increased with the addition of $N$ or $M$ particles per CGO particle. As expected, the surface area increases with the addition of the particles. More than 10x increase in surface area can be gained if $N=N_{\max }=17$ and $M=50$. The volume specific surface area for the CGO backbone with LSC coating without the additional particles is $1.1 \times 10^{7} \mathrm{~m}^{2} \mathrm{~m}^{-}$

${ }^{3}$. This value is already significantly higher than the estimated specific surface area for the conventional composite cathode $\left(8.33 \times 10^{5} \mathrm{~m}^{2} \mathrm{~m}^{-3}\right)$ discussed above. The corresponding increase on other parameters with the addition of LSC electrocatalysts, such as the area specific surface area and the LSC solid volume fraction are shown in Figs. $\underline{13} \mathrm{~b}$ and $\underline{13} \mathrm{c}$, respectively. The area specific surface area is defined as $A_{\mathrm{MIEC}} / A_{\mathrm{C}}\left(\mathrm{m}^{2} \mathrm{~m}^{-2}\right)$, where $A_{\mathrm{MIEC}}$ is total MIEC surface area and $A_{\mathrm{C}}$ is the geometrical area of the cathode $\left(1 \mathrm{~m}^{2}\right)$.

The addition of particles, however, also entails an increase in the occupancy of pores (decrease in the porosity) and could greatly affect the gas transport in the porous electrode. Fig. $13 \mathrm{~d}$ illustrates the effect at $600^{\circ} \mathrm{C}$. The addition of particles decreases $R_{\mathrm{p}}$ up to a certain point. The lowest $R_{\mathrm{p}}\left(0.092 \Omega \mathrm{cm}^{2}\right)$ can be obtained if the solid volume fraction of the LSC infiltrate is $\phi_{\mathrm{MIEC}}=0.72\left(A_{\mathrm{MIEC}} / A_{\mathrm{C}}=1.96 \times 10^{3} \mathrm{~m}^{2}\right.$ $\mathrm{m}^{-2}, \varepsilon=0.21$ ). Above this value, the $R_{\mathrm{p}}$ starts to increase as the gas transport limitation starts to dominate. Fig. 14a illustrates the decrease in the porosity with an increase in the amount of electrocatalysts. Fig. $\underline{14 \mathrm{~b}}$ shows the effect of the amount of electrocatalyst on the overall $R_{\mathrm{p}}$ at varying 
temperatures. It is seen that an increase in the amount of electrocatalyst $(M)$ decreases the $R_{\mathrm{p}}$ at low temperatures $\left(<600^{\circ} \mathrm{C}\right)$ but increases at high temperatures. At high temperatures, the resistance associated with oxygen reduction and transport of oxide ions is low and becomes comparable to the resistance associated with the transport of oxygen in the porous structure. This situation is reversed at low temperatures and the cathode is mainly dominated by the high resistance associated with the oxygen reduction and transport of oxide ions.

The effect of the ionic conductivity in the IC and MIEC phases

The oxide ion transport properties of the backbone and the infiltrate material are also very important in considering infiltrated cathodes. Fig. $\underline{15}$ shows the effect of the ionic conductivity of the infiltrate. The ionic conductivities are varied using the bulk ionic conductivity of the LSC as a base. It is seen that in order to have a significant decrease in $R_{\mathrm{p}}$, the bulk ionic conductivity has to be increased 100 times relative to that of the bulk LSC. At this high ionic conductivity, the oxide ions going to the electrolyte are most likely being transported in the MIEC rather than in the IC backbone which is consistent with the equivalent circuit shown in Fig. 4. At present there are no known MIEC that has $10-100$ times higher ionic conductivity than LSC and it thus represents a grossly exaggerated situation. Also shown in Fig. $\underline{15}$ is the effect on $R_{\mathrm{p}}$ when decreasing the bulk ionic conductivity of the LSC. In this calculation, it was necessary to add an oxide ion diffusion contribution to $r_{\mathrm{p}}$ as it is expected that this would play a major contribution once the ionic conductivity of the MIEC goes to very low values. The length to travel for the oxide ion through the MIEC towards the IC backbone is set to $y_{\text {coat }}=t_{\text {coat }}+r_{\text {coat }}$. Note that this is the maximum distance for oxide ion transport from the MIEC towards the IC backbone. The $r_{\mathrm{p}}$ in this case is defined as 
Fig. $\underline{16} \mathrm{a}$ and $\underline{16} \mathrm{~b}$ shows the effect of the ionic conductivity of the backbone on $R_{\mathrm{p}}$ for cathodes of thicknesses $25 \mu \mathrm{m}$ and $75 \mu \mathrm{m}$, respectively. It is seen that the corresponding increase or decrease in $R_{\mathrm{p}}$ is less than the corresponding factor of change in the ionic conductivity. This is because the other resistors shown in the equivalent circuit in Fig. 4 also contribute to the total $R_{\mathrm{p}}$. Going to a thicker cathode (Fig. $\underline{16} \mathrm{~b}$ ), the relative decrease in $R_{\mathrm{p}}$ especially at low temperatures becomes more significant when the ionic conductivity of the backbone is increased. The difference in the relative decrease in $R_{\mathrm{p}}$ for the two thicknesses when the ionic conductivity of the backbone is increased can be understood by the difference in the size of areas activated at low temperatures in the 25 and $75 \mu \mathrm{m}$ thick cathodes. In the $25 \mu \mathrm{m}$ thick cathode, the already high ionic diffusivity in the CGO backbone at low temperatures has most likely extended the active area to almost the entire electrode. A further increase in the ionic 
conductivity in this case only activates the rest of the volume slightly. This is clearly evident from the relatively small decrease in $R_{\mathrm{p}}$ at low temperatures when the ionic conductivity of the backbone is increased up to 100 times. For a thicker cathode (Fig. $\underline{16}$ b), the inactive volume is still large and an increase in ionic conductivity of the backbone causes a significant part of this to be activated which results in significantly lower values of $R_{\mathrm{p}}$.

Shown in Fig. $17 \mathrm{a}$ are the calculated $R_{\mathrm{p}}$ 's at different temperatures using various ionic conductors as backbones for a $25 \mu \mathrm{m}$ thick electrode considered in this model. The expressions used for the ionic conductivities of these materials are listed in Table 6. These expressions are extracted by fitting the experimental data from the corresponding list of references. The backbones considered in the model are $\mathrm{Ce}_{0.9} \mathrm{Gd}_{0.1} \mathrm{O}_{1.95}$ (CGO) [54], 8 mol \% yttria-stabilized zirconia (8YSZ) [71], $9.3 \mathrm{~mol} \% \mathrm{Sc}_{2} \mathrm{O}_{3}$ in $\mathrm{ZrO}_{2}$ (9.3ScSZ) [72], $\mathrm{La}_{0.9} \mathrm{Sr}_{0.1} \mathrm{Ga}_{0.9} \mathrm{Mg}_{0.1} \mathrm{O}_{3}$ (LSGM) [73], and $\mathrm{Bi}_{2} \mathrm{~V}_{0.1} \mathrm{Cu}_{0.8} \mathrm{O}_{5.35}$ (BICUVOX) [74]. It should be noted that the study is only focusing on the values of the ionic conductivity of the materials, thus the phase stability and reactivity of these materials with the infiltrate is not considered. Fig. 17a suggests trivially that in order to get the lowest $R_{\mathrm{p}}$, the backbone should have the highest ionic conductivity possible, pointing to BICUVOX. However, for this thickness, the gain in $R_{\mathrm{p}}$ is small especially at low temperatures, even for a ten-fold increase in the ionic conductivity e.g. by switching from CGO to BICUVOX. Shown in Fig. $15 \mathrm{~b}$ is the same data but using a thicker cathode $(75 \mu \mathrm{m})$ and Fig. $17 \mathrm{c}$ shows the $R_{\mathrm{p}}$ as a function of cathode thickness using CGO and BICUVOX backbones at 300 and $800{ }^{\circ} \mathrm{C}$. It is clear, especially at low temperatures that a significant advantage of having a BICUVOX backbone is only realized for very thick cathodes. A reduction of approximately 3 times in $R_{\mathrm{p}}$ can be obtained at low temperatures. As mentioned previously, this is because the other resistances (surface exchange properties) are also limiting the performance of the cathode. 
To examine the effect of the catalytic activity of the infiltrate, the $R_{\mathrm{p}}$ is examined as the area specific material surface exchange resistance at $T_{\max }=900{ }^{\circ} \mathrm{C}, r_{\mathrm{p}, \text { inf } 900}$, is varied. Fig. 18 shows the effect of increasing or decreasing $r_{\mathrm{p} \text {,inf } 900}$ on $R_{\mathrm{p}}$ for 25 and $75 \mu \mathrm{m}$ thick cathodes. As in the case of changing the ionic conductivity of the backbone, the amount of increase/decrease in $r_{\mathrm{p}, \text { inf } 900}$ does not correspond to an equivalent amount of change in $R_{\mathrm{p}}$. However, it is evident from Fig. 19 that compared to changing the bulk ionic conductivity of the backbone, the gain in performance at low temperatures (e.g. $\left.400^{\circ} \mathrm{C}\right)$ varies more strongly with the change in $r_{\mathrm{p}, \text { inf } 900}$ irrespective of the cathode thickness. This means that for this range of thicknesses, the ionic conductivity of the backbone is sufficient to transport the increased amount of oxide ions which were converted from oxygen in the surface of the MIEC due to the decrease in $r_{\mathrm{p}}$. For both thicknesses, the decrease in $R_{\mathrm{p}}$ is higher when $r_{\mathrm{p}, \text { inf } 900}$ is reduced than when the ionic conductivity of backbone is increased by the same factor. This result is somewhat expected as the ratio $r_{p, \text { inf } 900} /\left(L_{C} / \sigma_{i o, I C}^{\text {eff }}\right) \approx 132$ at $400^{\circ} \mathrm{C}$, where $\sigma_{i o, I C}^{\text {eff }}$ is the effective ionic conductivity of CGO as defined in Equation (30), suggests that the performance of the LSC infiltrated - CGO cathode is mainly limited by the oxygen exchange at the LSC infiltrate surface. For a $25 \mu \mathrm{m}$ thick cathode at $400^{\circ} \mathrm{C}$, the decrease in $R_{\mathrm{p}}$ by increasing the ionic conductivity 100 times that of CGO is $32 \%$ while that by decreasing the resistance associated with oxygen surface exchange 100 times that of the LSC infiltrate is $90 \%$. The significance of increasing the ionic conductivity of the backbone is realized for 
thicker cathodes as this increases the amount of the cathode that is active. Specifically, for a $75 \mu \mathrm{m}$ thick cathode at $400^{\circ} \mathrm{C}$, the decrease in $R_{\mathrm{p}}$ by increasing the ionic conductivity 100 times that of CGO is $86 \%$.

All the analysis performed above can also be applied for the infiltrated cathode fired at $600{ }^{\circ} \mathrm{C}$. It is expected to show the same tendencies but the values of $R_{\mathrm{p}}$ will be lower. Considering the available materials and techniques, we can look at particular targets for SOFC cathode performance, e.g. $R_{\mathrm{p}}$ of 1 $\Omega \mathrm{cm}^{2}$ at $400{ }^{\circ} \mathrm{C}$. To be able to attain this target with the present LSC - infiltrated CGO cathode, it is recommended to infiltrate a total of ca. $47 \mathrm{vol} \%$ of LSC into the CGO backbone ( $\mathrm{N}=125, \mathrm{M}=500$ in the geometrical respresentation). The resulting volume specific surface area of the infiltrate in this case is $1.58 \times 10^{8} \mathrm{~m}^{2} \mathrm{~m}^{-3}$ and the porosity, $\varepsilon=0.24$. The firing temperature has to be $600{ }^{\circ} \mathrm{C}$. In our experimental study reported in Ref. [31] , with the CGO backbone fired at $1050{ }^{\circ} \mathrm{C}$, only 12 vol \% LSC was incorporated into the backbone when a total of 6 infiltration cycles was performed. Additional infiltration by $12 x$ cycles only yielded 19 vol \% LSC. If the concentration of the LSC solution remained the same, incorporating $47 \mathrm{vol} \%$ of LSC would entail significantly high number of infiltration cycles. Further, it is found from the experimental measurements that the increased number of infiltration cycles from $6 \mathrm{x}$ to $12 \mathrm{x}$ do not result in lower $R_{\mathrm{p}}$ 's but increases slightly instead $\left(R_{\mathrm{p}}\right.$ 's at $400{ }^{\circ} \mathrm{C}$ : $6 \mathrm{x}$ infiltration $2.8 \Omega \mathrm{cm}^{2}$ and $12 \mathrm{x}$ infiltration $-2.9 \Omega \mathrm{cm}^{2}$ ). Apparently, in this case, it is not straightforward to achieve lower $R_{\mathrm{p}}$ 's via increased infiltration cycles. If we stay with 12 vol \% LSC and replace the CGO with BICUVOX, which exhibit $12 x$ faster ionic conductivity at $400{ }^{\circ} \mathrm{C}$, and assuming that it has the same microstructure, the $R_{\mathrm{p}}$ at $400{ }^{\circ} \mathrm{C}$ is $0.86 \Omega \mathrm{cm}^{2}$, better than the $1 \Omega \mathrm{cm}^{2}$ target. However, we have also shown experimentally [75], that this too might very difficult to implement. The low melting point 
of BICUVOX limits the attainment of a favorable microstructure and the poor chemical compatibility with LSC even at processing below $600{ }^{\circ} \mathrm{C}$ in the infiltration method results in a very high $R_{\mathrm{p}}$. If we stay with 12 vol \% LSC and CGO as the backbone, it would require that the current $r_{\mathrm{p}}$ of the LSC infiltrate be reduced to ca. 8 times to achieve $1 \Omega \mathrm{cm}^{2}$ at $400{ }^{\circ} \mathrm{C}$. Note that the $r_{\mathrm{p}}$ of Hayd et al.'s nanosized LSC is only about 4.5 times lower than the present LSC infiltrate at $400{ }^{\circ} \mathrm{C}$. A breakthrough in electrocatalyst materials is thus needed.

\section{Conclusion}

A 1-dimensional model based on the concepts of a random binary sphere model combined with geometrical considerations to represent the microstructure of infiltrates has been developed that can predict the polarization resistance of cathodes prepared by infiltration. The random binary sphere model was first used in the analysis of experimental data on a conventional LSC/CGO composite cathode to extract the material specific surface exchange resistance of LSC, $r_{\mathrm{p}}$. The value was found to be comparable to the values derived from LSC treatments in the form of porous electrodes or bars for conductivity relaxation measurements. The $r_{\mathrm{p}}$ lies below the values obtained from dense thin film model electrodes but above the value from nano-scaled cathodes. The thin coat model combined with this kinetic expression was used to estimate the polarization resistance of an LSC infiltrated cathode. For the infiltrated cathode fired at $600{ }^{\circ} \mathrm{C}$, the $r_{\mathrm{p}}$ was found to be lower than the derived value from the LSC/CGO conventional composite, while for the infiltrated cathode fired at $900{ }^{\circ} \mathrm{C}$, the $r_{\mathrm{p}}$ was found to be higher than the derived value from the LSC/CGO conventional composite. The $r_{\mathrm{p}}$ was higher for the infiltrated cathode fired at $900{ }^{\circ} \mathrm{C}$ compared to the same sample fired at $600{ }^{\circ} \mathrm{C}$. The difference can be 
attributed to changes in the phases comprising the "LSC" infiltrate brought about by increased firing temperature.

A series of parametric variations has been performed with the goal of presenting guidelines for developing a high performance cathode prepared by infiltration. It was shown that $R_{\mathrm{p}}$ decreases when the thickness of the cathode is increased up to a certain value due to increasing amount of electrocatalyst material that is available for surface exchange. Further increase in thickness would increase $R_{\mathrm{p}}$ due to increasing contribution of the gas transport resistance. The amount of infiltrated particles should be high enough not only to increase the surface area for oxygen surface exchange but to decrease the probability of loss of percolation when the infiltrated particles are fired at higher temperatures. At $600^{\circ} \mathrm{C}$, it is predicted that the lowest $R_{\mathrm{p}}\left(0.092 \Omega \mathrm{cm}^{2}\right)$ can be obtained if the solid volume fraction of the LSC infiltrate, $\phi_{\mathrm{MIEC}}=0.72\left(A_{\mathrm{MIEC}} / A_{\mathrm{C}}=1.96 \times 10^{3} \mathrm{~m}^{2} \mathrm{~m}^{-2}, \varepsilon=0.21\right)$. Above this value, the $R_{\mathrm{p}}$ increases due to increasing gas transport resistance. Concerning the ionic conductivity of infiltrates, it is predicted that the $R_{\mathrm{p}}$ at $600^{\circ} \mathrm{C}$ only increases by $11 \%$ even when the bulk ionic conductivity of the infiltrate is 1000 times less than LSC. Using the ionic conductivity of the CGO and the electrocatalytic activity of LSC infiltrate as base and other parameters constant, it was demonstrated that the gain in performance is greater with the increase in electrocatalytic activity than with the increase in ionic conductivity of the backbone.

\section{Acknowledgment}

This work was funded by the Department of Energy Conversion and Storage, Technical University of Denmark. 


\section{$\underline{\text { List of Symbols }}$}

$\underline{a \text { base radius of an } N \text { particle/ } \mathrm{m}}$

$\underline{A_{I C-M I E C}}$ specific surface area of the CGO backbone (IC) with the added coating/ $\mathrm{m}^{2} \mathrm{~m}^{-3}$

$\underline{A_{I C-M I E C}^{\text {particle }} \text { surface area of one IC particle with MIEC coating } / \mathrm{m}^{2}}$

$\underline{A_{0}}$ specific surface are based on solid volume $/ \mathrm{m}^{2} \mathrm{~m}^{-3}$

$\underline{A_{C} \text { unit area of the cathode/ } \mathrm{m}^{2}}$

$\underline{A_{\text {coat }} \text { cross sectional area of infiltrate coating } / \mathrm{m}^{2}}$

$\underline{A_{M I E C}(i) \text { active surface area of percolated MIEC in segment }(i) / \mathrm{m}^{2}}$

$\underline{A_{\text {MIEC }}^{s p} \text { specific surface area of percolated MIEC phase per unit volume/ } \mathrm{m}^{2} \mathrm{~m}^{-3}}$

$\underline{d}_{I C \text {, coat }}$ diameter of the IC particle with additional coating/ $\mathrm{m}$

$\underline{D}_{\mathrm{O}_{2}-\mathrm{N}_{2}}$ binary diffusion coefficient for oxygen and nitrogen $/ \mathrm{m}^{2} \mathrm{~s}^{-1}$

$\underline{D}_{\mathrm{O}_{2}-\mathrm{N}_{2}}^{\text {eff }}$ effective binary of oxygen and nitrogen $/ \mathrm{m}^{2} \mathrm{~s}^{-1}$

$\underline{D}_{\mathrm{O}_{2}-\mathrm{N}_{2}, \mathrm{~K}}^{\text {eff }}$ Knudsen diffusion coefficient for oxygen-nitrogen mixture/ $\mathrm{m}^{2} \mathrm{~s}^{-1}$

$\underline{d}_{c G O}$ diameter of CGO phase/ $\mathrm{m}$

$\underline{d_{h} \text { hydraulic diameter for porous electrode/ } \mathrm{m}}$

$\underline{d_{I C} \text { diameter of the ionic conducting (IC) phase/ } \mathrm{m}}$

$\underline{d_{L S C}}$ diameter of LSC phase/ m

$\underline{d}_{\text {MIEC }}$ diameter of the mixed ionic and electronic conducting phase (MIEC)/ $\mathrm{m}$

$\underline{d_{p} \text { pore diameter/ } \mathrm{m}}$

$\underline{F \text { Faraday constant }}$

$\underline{h \text { height of spherical caps protruding from the coating (called } N \text { particles)/ } \mathrm{m}}$ 
$\underline{I}_{i_{0}}-(i-1)$ equivalent current associated with the transport of oxide ions from segment $(i-1)$ to segment $(i) / \mathrm{A}$

$\underline{I_{e}-(i-1) \text { electronic current transported from segment }(i-1) \text { to segment }(i) / \mathrm{A}}$

$\underline{i_{\max } \text { maximum number electrode layer segmentation }}$

$\underline{i}_{M I E C}$ current generated through the electrode reaction per unit area/ $\mathrm{C} \mathrm{m}^{-2} \mathrm{~s}^{-1}$

$L_{N_{2}}(i)$ molar flux of nitrogen in segment $(i) / \mathrm{mol} \mathrm{m}^{-2} \mathrm{~s}^{-1}$

$L_{0^{2-},{ }_{16}}(i)$ molar flux of oxide ions in the IC phase into segment $(i) / \mathrm{mol} \mathrm{m}^{-2} \mathrm{~s}^{-1}$

$L_{O^{2-},{ }_{M I E G}}(i)$ molar flux of oxide ions in the MIEC phase into segment $(i) / \mathrm{mol} \mathrm{m}^{-2} \mathrm{~s}^{-1}$

$\mathrm{LO}_{2}(i)$ molar flux of oxygen into segment $(i) / \mathrm{mol} \mathrm{m}^{-2} \mathrm{~s}^{-1}$

$\underline{k_{\kappa} \text { Kozeny constant }}$

$\underline{L_{C}}$ cathode thickness/ m

$\underline{l}_{\text {coat }}$ length of the coating parallel to the CGO electrolyte/ $\mathrm{m}$

$\underline{m \text { Bruggeman factor }}$

$M$ particles attached from the infiltrate coating

$\underline{M_{N_{2}} \text { molecular mass of nitrogen } / \mathrm{kg} \mathrm{mol}^{-1}}$

$\underline{M_{\mathrm{O}_{2}} \text { molecular mass of oxygen } / \mathrm{kg} \mathrm{mol}^{-1}}$

$\underline{M_{\mathrm{O}_{2}-\mathrm{N}_{2}} \text { average molecular mass } / \mathrm{kg} \mathrm{mol}^{-1}}$

$\underline{N \text { particles protruding from the infiltrate coating }}$

$\underline{n_{I C} \text { number fraction of IC particles }}$

$\underline{n_{M I E C} \text { number fraction of MIEC particles }}$

$\underline{N_{t} \text { number density of all particles/ } \# \mathrm{~m}^{-3}}$

$p$ total pressure/ $\mathrm{Pa}$

$p_{N_{2}}$ (gas) partial pressure of nitrogen outside of cathode structure

$p_{\mathrm{O}_{2}}$ (gas) partial pressure of oxygen outside of cathode structure 
$\underline{P}_{i}$ probability of an i-phase belonging to a percolated network of the same phase $\underline{r \text { radius of } M \text { particle/ } m}$

$\underline{r}_{i o, L S C}$ resistance associated with the transport of oxide ions in the LSC infiltrate/ $\Omega$

$\underline{r}_{p, \text { inf } 900}$ area specific surface exchange resistance of the infiltrate fired at $T_{\max }=900^{\circ} \mathrm{C} / \Omega \mathrm{m}^{2}$

$\underline{r}_{p, M I E C}$ area specific resistance associated with oxygen exchange of MIEC phase/ $\Omega \mathrm{m}^{2}$

$\underline{R}_{e l}(i-1)$ electronic resistance for the transport of electrons from segment $(i-1)$ to segment $(i) / \Omega$

$\underline{R}_{i 0}(i-1)$ resistance associated with the transport of oxide ions from segment $(i-1)$ to segment $(i) / \Omega$

$r_{p}$ area specific resistance associated with oxygen exchange/ $\Omega \mathrm{m}^{2}$

$R_{p}$ area specific polarization resistance $/ \Omega \mathrm{m}^{2}$

$\underline{s \text { surface area factor }}$

$\underline{T \text { temperature/ } \mathrm{K}}$

$\underline{t}_{\text {coat }}$ coating thickness, infiltrated electrocatalyst $/ \mathrm{m}$

$\underline{V(i) \text { volume in segment }(\mathrm{i}) / \mathrm{m}^{3}}$

${\underline{N_{2}}}_{\mathrm{N}_{2}}$ diffusion volume for nitrogen

$\underline{V}_{O_{2}}$ diffusion volume for oxygen

$\underline{x_{N_{2}} \text { molar fraction of nitrogen }}$

$\underline{x}_{\mathrm{O}_{2}}$ molar fraction of oxygen

$y_{\text {coat }}$ length to travel for the oxide ion through the MIEC towards the IC backbone/ $\mathrm{m}$

$\underline{Z_{i-j}}$ coordination number between an $i$-phase particle and a $j$-phase particle

$\underline{Z_{I C}}$ average total coordination number for MIEC particles

$\underline{Z}_{\text {MIEC }}$ average total coordination number for MIEC particles

\section{$\underline{\text { Greek letters }}$}


$\alpha$ ratio between the diameters of IC to MIEC particles

$\Delta x_{(i-1)-(1)}$ distance of segment $(i-1)$ and segment $(i) / \mathrm{m}$

$\underline{\varepsilon \text { porosity of the electrode }}$

$\eta$ overpotential/ V

$\eta_{e l}$ electric overpotential/ V

$\eta_{i o}$ ionic overpotential/ V

$\eta_{\text {gas }}$ gas concentration overpotential/ V

$\underline{\theta_{c} \text { contact angle between particles/ }}{ }^{\circ}$

$\mu_{N_{2}}$ viscosity of nitrogen/ $\mathrm{Pa} \mathrm{s}$

$\mu_{\mathrm{O}_{2}}$ viscosity of oxygen/ $\mathrm{Pa} \mathrm{s}$

$\mu_{\mathrm{O}_{2}-\mathrm{N}_{2}}$ average viscosity of oxygen and nitrogen mixture

$\sigma_{i}^{0}$ bulk conductivity of phase $i / \mathrm{S} \mathrm{m}^{-1}$

$\sigma_{\text {el,MIEC }}^{e f f}$ effective electronic conductivity in the MIEC phase/ $\mathrm{S} \mathrm{m}^{-1}$

$\sigma_{i}^{e f f}$ effective conductivity of phase $i / \mathrm{S} \mathrm{m}^{-1}$

$\underline{\sigma}_{i \theta, I C}^{e f f}$ effective ionic conductivity in the IC phase/ $\mathrm{S} \mathrm{m}^{-1}$

$\underline{\tau \text { tortuosity }}$

$\phi_{i}$ solid volume fraction of phase $i$

$\phi_{I C}$ solid volume fraction of the IC phase

$\phi_{\text {MIEC }}$ solid volume fraction of the MIEC phase

\section{References}


[1] B.C.H. Steele, A. Heinzel, Materials for fuel-cell technologies, Nature 414 (2001) 345-352.

[2] M.C. Tucker, Progress in metal-supported solid oxide fuel cells: A review, J. Power Sources 195 (2010) 4570-4582.

[3] H.U. Anderson, F. Tietz, in: Singhal S.C., Kendall K. (Eds.), High temperature soild oxide fuel cells: Fundamentals, design and applications, Elsevier Advanced Technology, Oxford, U.K., 2003,.

[4] Y.C. Hsiao, J.R. Selman, The degradation of SOFC electrodes, Solid State Ionics 98 (1997) 33-38.

[5] P. Tanasini, M. Cannarozzo, P. Costamagna, A. Faes, J. Van Herle, A. Hessler-Wyser, et al., Experimental and Theoretical Investigation of Degradation Mechanisms by Particle Coarsening in SOFC Electrodes, Fuel Cells 9 (2009) 740-752.

[6] S. Ghosh, A.D. Sharma, R.N. Basu, H.S. Maiti, Influence of B site Substituents on Lanthanum Calcium Chromite Nanocrystalline Materials for a Solid-Oxide Fuel Cell, J Am Ceram Soc 90 (2007) 3741-3747.

[7] C. Endler-Schuck, A. Leonide, A. Weber, S. Uhlenbruck, F. Tietz, E. Ivers-Tiffée, Performance analysis of mixed ionic-electronic conducting cathodes in anode supported cells, J. Power Sources 196 (2011) 7257-7262.

[8] A. Mai, M. Becker, W. Assenmacher, F. Tietz, D. Hathiramani, E. Ivers-Tiffée, et al., Timedependent performance of mixed-conducting SOFC cathodes, Solid State Ionics 177 (2006) 19651968.

[9] M.J.L. Østergård, C. Clausen, C. Bagger, M. Mogensen, Manganite-zirconia composite cathodes for SOFC: Influence of structure and composition, Electrochim. Acta 40 (1995) 1971-1981.

[10] E.P. Murray, T. Tsai, S.A. Barnett, Oxygen transfer processes in ( $\mathrm{La}, \mathrm{Sr}) \mathrm{MnO} 3 / \mathrm{Y} 2 \mathrm{O} 3$-stabilized ZrO2 cathodes: an impedance spectroscopy study, Solid State Ionics 110 (1998) 235-243.

[11] V. Dusastre, J.A. Kilner, Optimisation of composite cathodes for intermediate temperature SOFC applications, Solid State Ionics 126 (1999) 163-174.

[12] E. Perry Murray, M.J. Sever, S.A. Barnett, Electrochemical performance of $(\mathrm{La}, \mathrm{Sr})(\mathrm{Co}, \mathrm{Fe}) \mathrm{O} 3-$ (Ce,Gd)O3 composite cathodes, Solid State Ionics 148 (2002) 27-34.

[13] W.G. Wang, M. Mogensen, High-performance lanthanum-ferrite-based cathode for SOFC, Solid State Ionics 176 (2005) 457-462.

[14] C. Xia, M. Liu, Low-temperature SOFCs based on Gd0.1Ce 0.901 .95 fabricated by dry pressing, Solid State Ionics 144 (2001) 249-255. 

Temperature SOFCs, J. Electrochem. Soc. 158 (2011) B1076-B1082.

[16] A. Tarancón, J. Peña-Martínez, D. Marrero-López, A. Morata, J.C. Ruiz-Morales, P. Núñez, Stability, chemical compatibility and electrochemical performance of $\mathrm{GdBaCo} 2 \mathrm{O} 5+\mathrm{x}$ layered perovskite as a cathode for intermediate temperature solid oxide fuel cells, Solid State Ionics 179 (2008) 2372-2378.

[17] K. Wang, R. Ran, W. Zhou, H. Gu, Z. Shao, J. Ahn, Properties and performance of $\mathrm{Ba} 0.5 \mathrm{Sr} 0.5 \mathrm{Co} 0.8 \mathrm{Fe} 0.2 \mathrm{O} 3-\delta+\mathrm{Sm} 0.2 \mathrm{Ce} 0.8 \mathrm{O} 1.9$ composite cathode, J. Power Sources 179 (2008) 6068.

[18] J.H. Kim, M. Cassidy, J.T.S. Irvine, J. Bae, Advanced Electrochemical Properties of LnBa[sub $0.5] \mathrm{Sr}$ [sub 0.5] Co[sub 2] O[sub $5+$ delta] $(\mathrm{Ln}=\mathrm{Pr}, \mathrm{Sm}$, and $\mathrm{Gd})$ as Cathode Materials for IT-SOFC, J. Electrochem. Soc. 156 (2009) B682-B689.

[19] Y. Tao, J. Shao, W.G. Wang, J. Wang, Optimisation and Evaluation of La0.6Sr0.4CoO3???? Cathode for Intermediate Temperature Solid Oxide Fuel Cells, Fuel Cells 9 (2009) 679-683.

[20] S.B. Adler, J.A. Lane, B.C.H. Steele, Electrode Kinetics of Porous Mixed-Conducting Oxygen Electrodes, J. Electrochem. Soc. 143 (1996) 3554-3564.

[21] J. Fleig, SOLID OXIDE FUEL CELL CATHODES: Polarization Mechanisms and Modeling of the Electrochemical Performance, Annual Review of Materials Research 33 (2003) 361-382.

[22] J.M. Vohs, R.J. Gorte, High-Performance SOFC Cathodes Prepared by Infiltration, Adv Mater 21 (2009) 943-956.

[23] Z. Jiang, C. Xia, F. Chen, Nano-structured composite cathodes for intermediate-temperature solid oxide fuel cells via an infiltration/impregnation technique, Electrochim. Acta 55 (2010) 3595-3605.

[24] J. San Ping, Nanoscale and nano-structured electrodes of solid oxide fuel cells by infiltration: Advances and challenges, Int J Hydrogen Energy 37 (2012) 449-470.

[25] T.Z. Sholklapper, C.P. Jacobson, S.J. Visco, L.C. De Jonghe, Synthesis of Dispersed and Contiguous Nanoparticles in Solid Oxide Fuel Cell Electrodes, Fuel Cells 8 (2008) 303-312.

[26] Y. Huang, J.M. Vohs, R.J. Gorte, Characterization of LSM-YSZ Composites Prepared by Impregnation Methods, J. Electrochem. Soc. 152 (2005) A1347-A1353.

[27] Y. Huang, K. Ahn, J.M. Vohs, R.J. Gorte, Characterization of Sr-Doped LaCoO[sub 3]-YSZ Composites Prepared by Impregnation Methods, J. Electrochem. Soc. 151 (2004) A1592-A1597. 

La0.6Sr0.4Co0.2Fe0.8O3 - $\delta$ into Gd-Doped Ceria, Solid State Ionics 179 (2008) 2059-2064.

[29] F. Zhao, R. Peng, C. Xia, A La0.6Sr0.4CoO3- $\delta$-based electrode with high durability for intermediate temperature solid oxide fuel cells, Mater. Res. Bull. 43 (2008) 370-376.

[30] F. Zhao, R. Peng, C. Xia, LSC-based electrode with high durability for IT-SOFCs, Fuel Cells Bulletin 2008 (2008) 12-16.

[31] A. Samson, M. Sogaard, R. Knibbe, N. Bonanos, High Performance Cathodes for Solid Oxide Fuel Cells Prepared by Infiltration of La[sub 0.6] $\mathrm{Sr}[\mathrm{sub} 0.4] \mathrm{CoO}[\mathrm{sub} 3$ - delta ] into Gd-Doped Ceria, J. Electrochem. Soc. 158 (2011) B650-B659.

[32] T. Kenjo, S. Osawa, K. Fujikawa, High Temperature Air Cathodes Containing Ion Conductive Oxides, J. Electrochem. Soc. 138 (1991) 349-355.

[33] C.W. Tanner, K. Fung, A.V. Virkar, The Effect of Porous Composite Electrode Structure on Solid Oxide Fuel Cell Performance, J. Electrochem. Soc. 144 (1997) 21-30.

[34] J.H. Nam, D.H. Jeon, A comprehensive micro-scale model for transport and reaction in intermediate temperature solid oxide fuel cells, Electrochim. Acta 51 (2006) 3446-3460.

[35] S. Farhad, F. Hamdullahpur, Optimization of the microstructure of porous composite cathodes in solid oxide fuel cells, AICHE J. (2011) n/a-n/a.

[36] X.J. Chen, S.H. Chan, K.A. Khor, Simulation of a composite cathode in solid oxide fuel cells, Electrochim. Acta 49 (2004) 1851-1861.

[37] P. Costamagna, P. Costa, V. Antonucci, Micro-modelling of solid oxide fuel cell electrodes, Electrochim. Acta 43 (1998) 375-394.

[38] F. Bidrawn, R. Kungas, J.M. Vohs, R.J. Gorte, Modeling Impedance Response of SOFC Cathodes Prepared by Infiltration, J. Electrochem. Soc. 158 (2011) B514-B525.

[39] M. Shah, J.D. Nicholas, S.A. Barnett, Prediction of infiltrated solid oxide fuel cell cathode polarization resistance, Electrochemistry Communications 11 (2009) 2-5.

[40] M. Søgaard, P.V. Hendriksen, T. Jacobsen, M. Mogensen, Modeling of the polarization resistance from surface exchange and diffusion coeffficient data, 7th European SOFC Forum, Session B06, Wednesday, 5 July, 11:45h, File No. B064 (2006).

[41] H.J.M. - Bouwmeester, C. - Song, J. - Zhu, J. - Yi, M. - van Sint Annaland, B.A. - Boukamp, - A novel pulse isotopic exchange technique for rapid determination of the oxygen surface exchange rate of oxide ion conductors, - Phys. Chem. Chem. Phys. - 9640. 

Oxygen surface exchange, Solid State Ionics 126 (1999) 153-161.

[43] M. Søgaard, P. Vang Hendriksen, M. Mogensen, Oxygen nonstoichiometry and transport properties of strontium substituted lanthanum ferrite, Journal of Solid State Chemistry 180 (2007) 1489-1503.

[44] J.E. ten Elshof, M.H.R. Lankhorst, H.J.M. Bouwmeester, Oxygen Exchange and Diffusion Coefficients of Strontium-Doped Lanthanum Ferrites by Electrical Conductivity Relaxation, J. Electrochem. Soc. 144 (1997) 1060-1067.

[45] L.M. van der Haar, M.W. den Otter, M. Morskate, H.J.M. Bouwmeester, H. Verweij, Chemical Diffusion and Oxygen Surface Transfer of La[sub 1 - x]Sr[sub x]CoO[sub 3 - delta] Studied with Electrical Conductivity Relaxation, J. Electrochem. Soc. 149 (2002) J41-J46.

[46] B.T. Dalslet, M. Sogaard, P.V. Hendriksen, Determination of Oxygen Transport Properties from Flux and Driving Force Measurements, J. Electrochem. Soc. 154 (2007) B1276-B1287.

[47] F.S. Baumann, J. Fleig, H. Habermeier, J. Maier, Impedance spectroscopic study on well-defined $(\mathrm{La}, \mathrm{Sr})(\mathrm{Co}, \mathrm{Fe}) \mathrm{O} 3-\delta$ model electrodes, Solid State Ionics 177 (2006) 1071-1081.

[48] M. Suzuki, T. Oshima, Estimation of the Co-ordination number in a Multi-Component Mixture of Spheres, Powder Technol 35 (1983) 159-166.

[49] D. Bouvard, F.F. Lange, Relation between percolation and particle coordination in binary powder mixtures, Acta Metallurgica et Materialia 39 (1991) 3083-3090.

[50] C. Kuo, P.K. Gupta, Rigidity and conductivity percolation thresholds in particulate composites, Acta Metallurgica et Materialia 43 (1995) 397-403.

[51] H. He, Y. Huang, J. Regal, M. Boaro, J.M. Vohs, R.J. Gorte, Low-Temperature Fabrication of Oxide Composites for Solid-Oxide Fuel Cells, J Am Ceram Soc 87 (2004) 331-336.

[52] J. Sanyal, G.M. Goldin, H. Zhu, R.J. Kee, A particle-based model for predicting the effective conductivities of composite electrodes, J. Power Sources 195 (2010) 6671-6679.

[53] M. Søgaard, P.V. Hendriksen, M. Mogensen, F.W. Poulsen, E. Skou, Oxygen nonstoichiometry and transport properties of strontium substituted lanthanum cobaltite, Solid State Ionics 177 (2006) 3285-3296.

[54] B. Dalslet, P. Blennow, P.V. Hendriksen, N. Bonanos, D. Lybye, M. Mogensen, Assessment of doped ceria as electrolyte, Journal of Solid State Electrochemistry 10 (2006) 547-561. 
[55] P.S. Jørgensen, K.V. Hansen, R. Larsen, J.R. Bowen, A framework for automatic segmentation in three dimensions of microstructural tomography data, Ultramicroscopy 110 (2010) 216-228.

[56] D.H. Jeon, J.H. Nam, C. Kim, Microstructural Optimization of Anode-Supported Solid Oxide Fuel Cells by a Comprehensive Microscale Model, J. Electrochem. Soc. 153 (2006) A406-A417.

[57] E.A. Mason, A.P. Malinauskas, Gas Transport in Porous Media: The Dusty Gas Model, Elsevier, New York, 1983.

[58] E.A. Mason, H.K. Lonsdale, Statistical-mechanical theory of membrane transport, J. Membr. Sci. 51 (1990) 1-81.

[59] R.E. Williford, L.A. Chick, G.D. Maupin, S.P. Simner, J.W. Stevenson, Diffusion Limitations in the Porous Anodes of SOFCs, J. Electrochem. Soc. 150 (2003) A1067-A1072.

[60] E.N. Fuller, P.D. Schettler, J.C. Giddings, New method for prediction of binary gas-phase diffusion coefficients , Ind. Eng. Chem. 58 (1966) 18.

[61] B. Todd, J.B. Young, Thermodynamic and transport properties of gases for use in solid oxide fuel cell modelling, J. Power Sources 110 (2002) 186-200.

[62] R.B. Bird, W.E. Stewart, E.N. Lightfoot, Transport Phenomena, 2nd ed., Wiley \& Sons, New York, 2002.

[63] F.S. Baumann, J. Fleig, G. Cristiani, B. Stuhlhofer, H.-. Habermeier, J. Maier, Quantitative Comparison of Mixed Conducting SOFC Cathode Materials by Means of Thin Film Model Electrodes, J. Electrochem. Soc. 154 (2007) B931-B941.

[64] S.B. Adler, Mechanism and kinetics of oxygen reduction on porous La1-xSrxCoO3- $\delta$ electrodes, Solid State Ionics 111 (1998) 125-134.

[65] J. Hayd, A. Weber, E. Ivers-Tiffée, Modified oxygen surface-exchange properties by nanoparticulate $\mathrm{Co}_{3} \mathrm{O}_{4}$ and $\mathrm{SrO}$ in $\mathrm{La}_{0.6} \mathrm{Sr}_{0.4} \mathrm{CoO}_{3-\mathrm{x}}$ thin-film cathodes, 10 th European SOFC Forum, Session B0411, 26 - 29 June (2012).

[66] J.E. Mortensen, M. Søgaard, T. Jacobsen, Analytical, 1-Dimensional Impedance Model of a Composite Solid Oxide Fuel Cell Cathode, Journal of The Electrochemical Society 161 (2014) F161F175.

[67] M. Kubicek, A. Limbeck, T. Fromling, H. Hutter, J. Fleig, Relationship between Cation Segregation and the Electrochemical Oxygen Reduction Kinetics of La[sub 0.6]Sr[sub 0.4]CoO[sub 3 delta ] Thin Film Electrodes, J. Electrochem. Soc. 158 (2011) B727-B734. 
[68] S.H. Chan, X.J. Chen, K.A. Khor, Cathode Micromodel of Solid Oxide Fuel Cell, J. Electrochem. Soc. 151 (2004) A164-A172.

[69] Y. Lin, C. Nan, Y. Liu, J. Li, T. Mizokawa, Z. Shen, High-Temperature Electrical Transport and Thermoelectric Power of Partially Substituted Ca3Co4O9-Based Ceramics, J Am Ceram Soc 90 (2007) 132-136.

[70] S. - Sakamoto, M. - Yoshinaka, K. - Hirota, O. - Yamaguchi, - Fabrication, Mechanical Properties, and Electrical Conductivity of Co3O4 Ceramics, - Journal of the American Ceramic Society - 80 (1997) - 267-- 268.

[71] M. Mori, T. Abe, H. Itoh, O. Yamamoto, Y. Takeda, T. Kawahara, Cubic-stabilized zirconia and alumina composites as electrolytes in planar type solid oxide fuel cells, Solid State Ionics 74 (1994) $157-164$

[72] S.P.S. Badwal, F.T. Ciacchi, D. Milosevic, Scandia-zirconia electrolytes for intermediate temperature solid oxide fuel cell operation, Solid State Ionics 136-137 (2000) 91-99.

[73] - Doped LaGaO3 Perovskite Type Oxide as a New Oxide Ionic Conductor, - Journal of the American Chemical Society - 3801.

[74] F. Abraham, J.C. Boivin, G. Mairesse, G. Nowogrocki, The bimevox series: A new family of high performances oxide ion conductors, Solid State Ionics 40-41 (1990) 934-937.

[75] A.J. Samson, M. Søgaard, N. Bonanos, Electrochemical characterization of infiltrated Bi2V0.9Cu0.1O5.35 cathodes for use in low temperature solid oxide fuel cells, Solid State Ionics 211 (2012) 74-79. 


\begin{tabular}{ccc} 
Material & Ionic Conductivity/ $\mathrm{S} \mathrm{m}^{-1}$ & Reference \\
\hline CGO & $\frac{1.34 \times 10^{7}}{T} \exp \left(-\frac{64799}{R T}\right)$ & {$[54]$} \\
LSC & $\frac{4.26 \times 10^{9}}{T} \exp \left(-\frac{121659}{R T}\right)$ & [53] \\
\hline
\end{tabular}

Table 1. Bulk conductivity expressions used in modeling the conventional composite cathode.

\begin{tabular}{cc} 
Parameter & Value \\
\hline$d_{L S C}$ & $1300 \mathrm{~nm}$ \\
$d_{C G O}$ & $1300 \mathrm{~nm}$ \\
$L_{C}$ & $15 \mu \mathrm{m}$ \\
$\varepsilon$ & 0.21 \\
$\phi_{L S C}$ & 0.52 \\
$\phi_{C G O}$ & 0.48 \\
$\theta_{C}$ & $70^{\circ}$ \\
\hline
\end{tabular}

Table 2. Microstructural parameters used in modeling the conventional composite cathode.

\begin{tabular}{cc} 
Parameter & Value \\
\hline$d_{C G O}$ & $200 \mathrm{~nm}$ \\
$L_{C}$ & $25 \mu \mathrm{m}$ \\
$\varepsilon$ & 0.59 \\
$\tau$ & 3 \\
$\theta_{c}$ & $30^{\circ}$ \\
$t_{\text {coat }}$ & $5 \mathrm{~nm}$ \\
$r_{\text {LSC }}$ & $15 \mathrm{~nm}\left(T_{\max }=600^{\circ} \mathrm{C}\right)$ \\
& $40 \mathrm{~nm}\left(T_{\max }=900^{\circ} \mathrm{C}\right)$ \\
$\mathrm{N}$ & $125\left(T_{\max }=600^{\circ} \mathrm{C}\right)$ \\
& $10\left(T_{\max }=900^{\circ} \mathrm{C}\right)$ \\
$\mathrm{M}$ & 0 \\
\hline
\end{tabular}

Table 3. Microstructural parameters used in modeling the infiltrated cathode. 


\begin{tabular}{lccc}
\multicolumn{1}{c}{$r_{\mathrm{p}}$} & $c_{2} / \mathrm{kJ} \mathrm{mol}^{-1}$ & $\begin{array}{c}r_{p} \text { at } 750{ }^{\circ} \mathrm{C} / \Omega \\
\mathrm{cm}^{2}\end{array}$ & $R_{\mathrm{p}}$ at $750{ }^{\circ} \mathrm{C} / \Omega \mathrm{cm}^{2}$ \\
\hline Binary sphere model (LSC/CGO composite) [This & 130 & 0.23 & 0.038 \\
work] & & & 0.49 \\
Baumann et al. (LSC thin film) [57] & 126 & 5.9 & 0.027 \\
Mortensen et al. (LSC/CGO composite) [66] & 125 & 0.13 & 0.029 \\
Søgaard et al. (Bulk LSC) [53] & 212 & 0.14 & 0.059 \\
Adler (Porous LSC)[64] & 93 & 0.47 & 0.004 \\
Hayd et al. (Nano-scaled LSC)[65] & 155 & 0.0035 & \\
\hline
\end{tabular}

Table 4. Activation energies of the extracted $r_{\mathrm{p}}$ from the study compared to those derived from literature. The expected $R_{\mathrm{p}}$ at $750{ }^{\circ} \mathrm{C}$ is also shown for each $r_{\mathrm{p}}$ input. The experimental $R_{\mathrm{p}}$ at 750 ${ }^{\circ} \mathrm{C}$ is $0.035 \Omega \mathrm{cm}^{2}$.

\begin{tabular}{|c|c|c|c|c|}
\hline \multirow{3}{*}{$r_{\mathrm{p}}$} & \multirow{3}{*}{$\begin{array}{l}c_{2} / \mathrm{kJ} \\
\mathrm{mol}^{-1}\end{array}$} & \multicolumn{3}{|c|}{$R_{\mathrm{p}}$ at $600{ }^{\circ} \mathrm{C} / \Omega \mathrm{cm}^{2}$} \\
\hline & & $r_{p}$ at $600{ }^{\circ} \mathrm{C} /$ & $T_{\max }=600$ & $T_{\max }=900^{\circ} \mathrm{C}$ \\
\hline & & $\Omega \mathrm{cm}^{2}$ & ${ }^{\circ} \mathrm{C}$ & \\
\hline Thin coat model, Tmax $=600{ }^{\circ} \mathrm{C}$ [This work $]$ & 111 & 2.25 & 0.071 & 0.081 \\
\hline $\operatorname{Tmax}=900^{\circ} \mathrm{C}[$ This work $]$ & 110 & 8.10 & & 0.153 \\
\hline Binary sphere model (LSC/CGO composite) [This & 130 & 3.15 & $\underline{0.082}$ & $\underline{0.094}$ \\
\hline work] & & & & \\
\hline Baumann et al. (LSC thin film) [57] & 126 & 74 & 0.0404 & 0.463 \\
\hline Mortensen et al. (LSC/CGO composite) [66] & 125 & 1.6 & 0.059 & 0.068 \\
\hline Adler (Porous LSC)[64] & 93 & 3.1 & 0.084 & 0.096 \\
\hline Hayd et al. (Nano-scaled LSC)[65] & 155 & 0.08 & 0.014 & 0.017 \\
\hline
\end{tabular}

Table 5. Activation energies of the extracted $r_{\mathrm{p}}$ from the infiltrated cathode compared to those derived from literature. The expected $R_{\mathrm{p}}$ at $750{ }^{\circ} \mathrm{C}$ is also shown for each $r_{\mathrm{p}}$. The experimental $R_{\mathrm{p}}{ }^{\prime}$ s at $600{ }^{\circ} \mathrm{C}$ are $0.075 \Omega \mathrm{cm}^{2}$ at $T_{\max }=600{ }^{\circ} \mathrm{C}$ and $0.14 \Omega \mathrm{cm}^{2}$ at $T_{\max }=900{ }^{\circ} \mathrm{C}$. 


\begin{tabular}{|c|c|c|c|c|c|c|}
\hline \multirow[b]{2}{*}{ Backbone } & \multicolumn{2}{|c|}{$\sigma=\frac{\sigma_{0}}{T} \exp \left(-\frac{E_{A}}{R T}\right)$} & \multicolumn{3}{|c|}{$\sigma\left(S m^{-1}\right)$} & \multirow[b]{2}{*}{ Reference } \\
\hline & $\sigma_{0}\left(S m^{-1}\right)$ & $E_{A}\left(J \mathrm{~mol}^{-1}\right)$ & $400{ }^{\circ} \mathrm{C}$ & $600{ }^{\circ} \mathrm{C}$ & $800^{\circ} \mathrm{C}$ & \\
\hline $\mathrm{CGO}$ & $1.3 \times 10^{7}$ & $6.5 \times 10^{4}$ & 0.19 & 2.0 & 8.8 & [47] \\
\hline 8YSZ & $1.4 \times 10^{8}$ & $9.1 \times 10^{3}$ & 0.016 & 0.53 & 4.5 & [63] \\
\hline 9.3ScSZ & $1.1 \times 10^{9}$ & $9.8 \times 10^{4}$ & 0.04 & 1.7 & 17 & [64] \\
\hline LSGM & $1.8 \times 10^{7}$ & $6.8 \times 10^{4}$ & 0.14 & 1.7 & 7.9 & [65] \\
\hline BICUVOX $(<$ & & & & & & \\
\hline$\left.{ }^{\circ} \mathrm{C}\right)$ & $5.1 \times 10^{7}$ & $5.8 \times 10^{4}$ & 2.3 & & & [66] \\
\hline$\left.{ }^{\circ} \mathrm{C}\right)$ & $9.1 \times 10^{5}$ & $3.3 \times 10^{4}$ & & 11 & 21 & [66] \\
\hline
\end{tabular}

Table 6. Expressions used for the ionic conductivity of the backbones. The expressions are obtained by fitting the corresponding data from the listed references. 

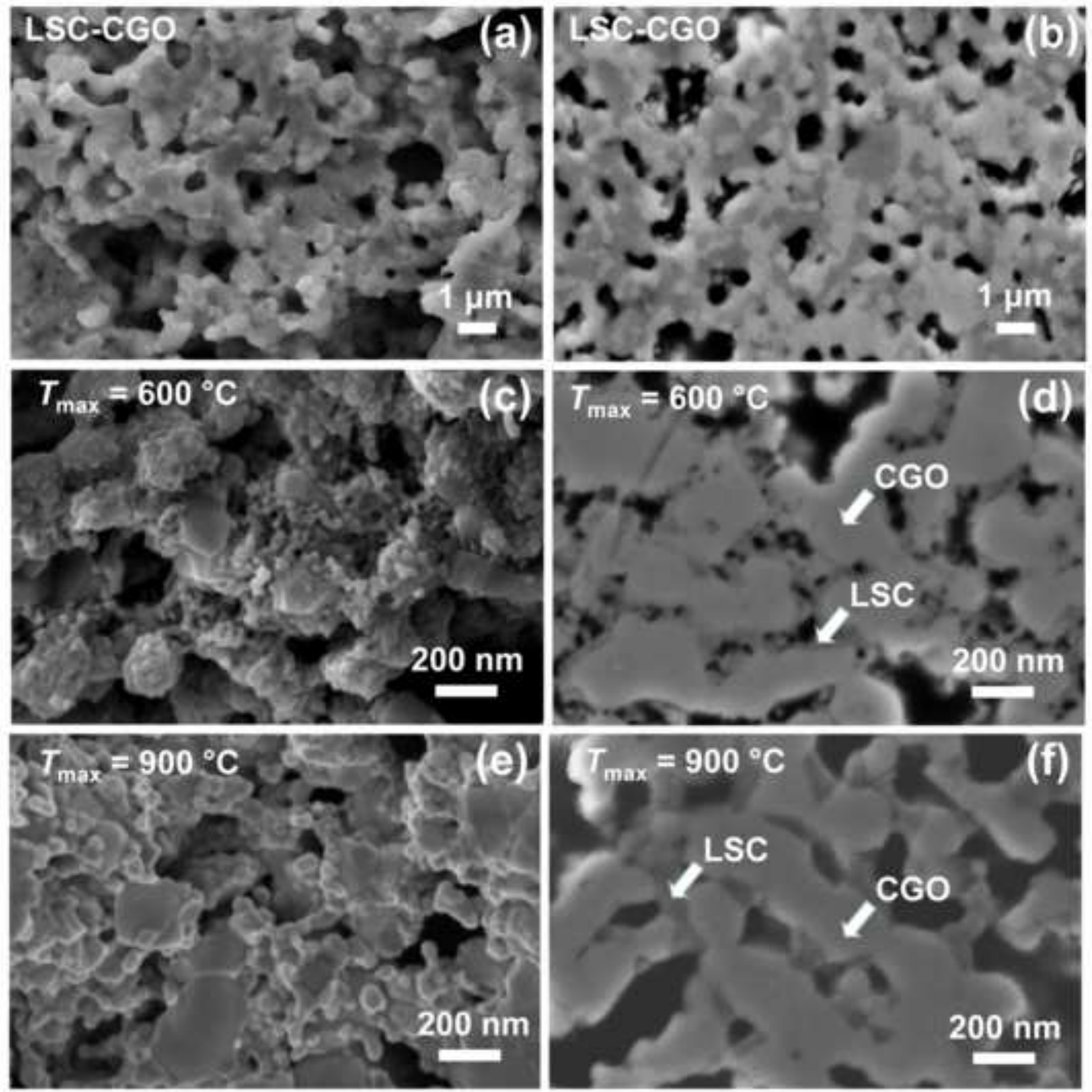

$200 \mathrm{~nm}$ 
(a)

(b)

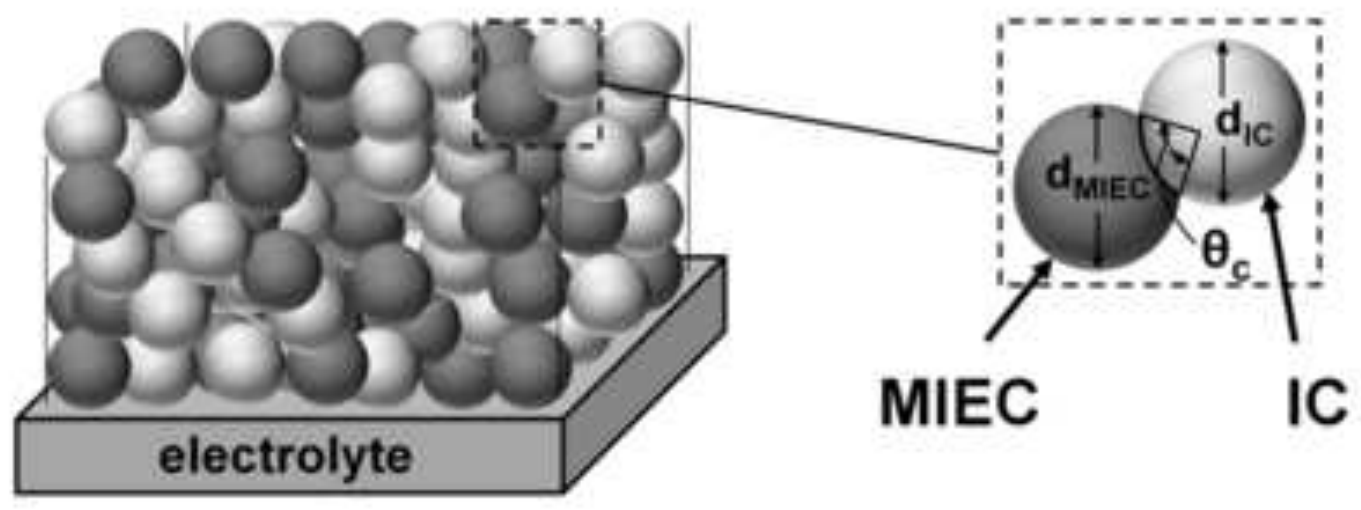

(c)

(d)

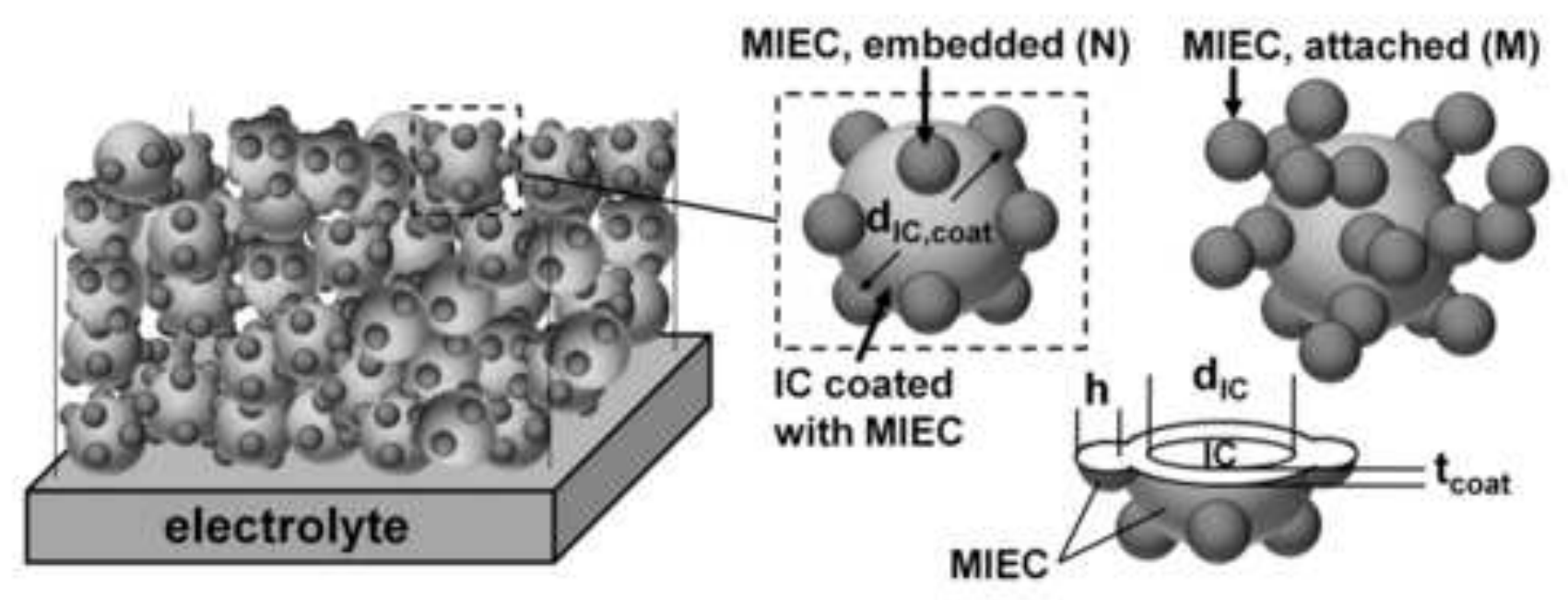




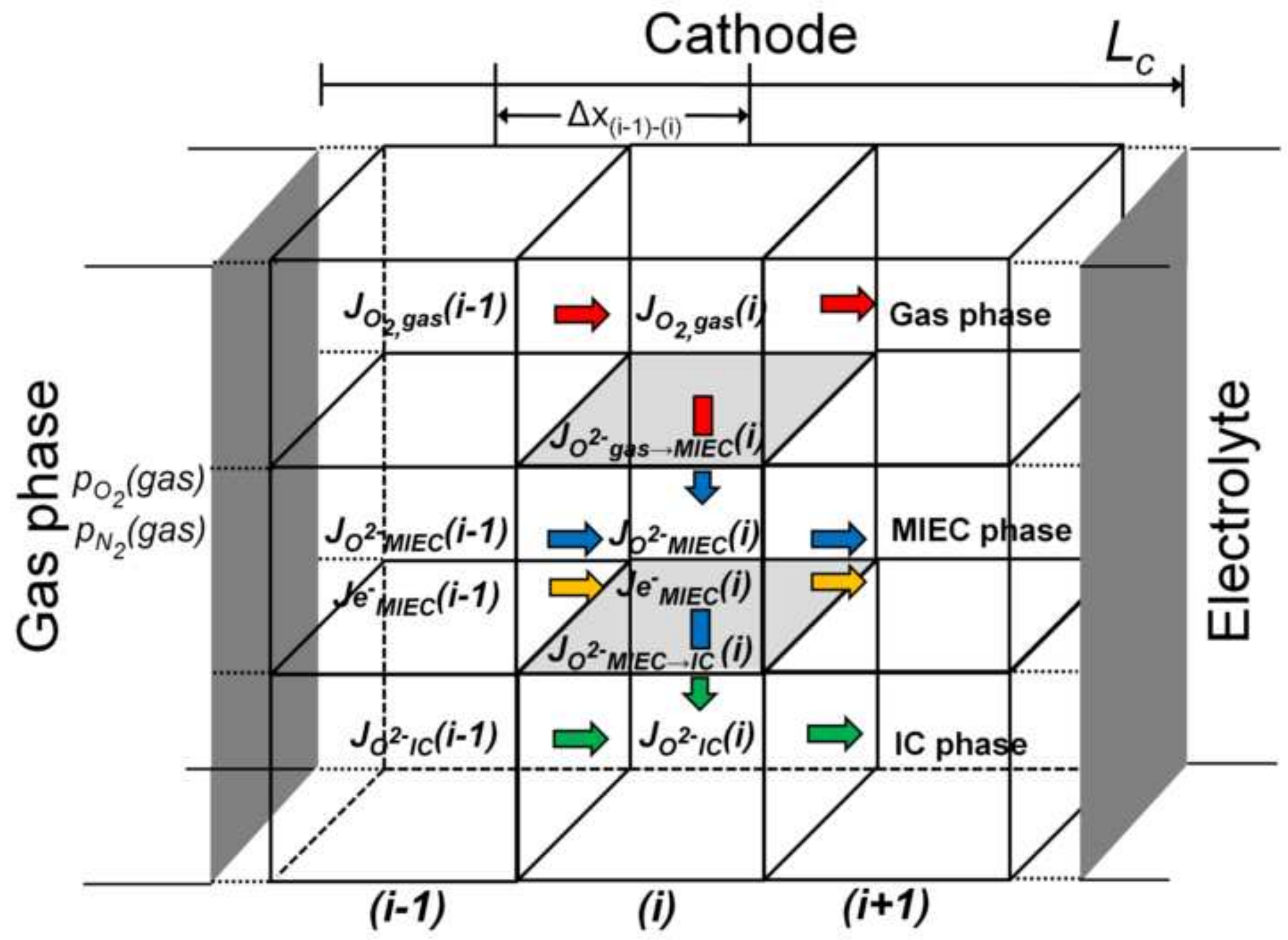




\section{Cathode $\quad L_{c}$}

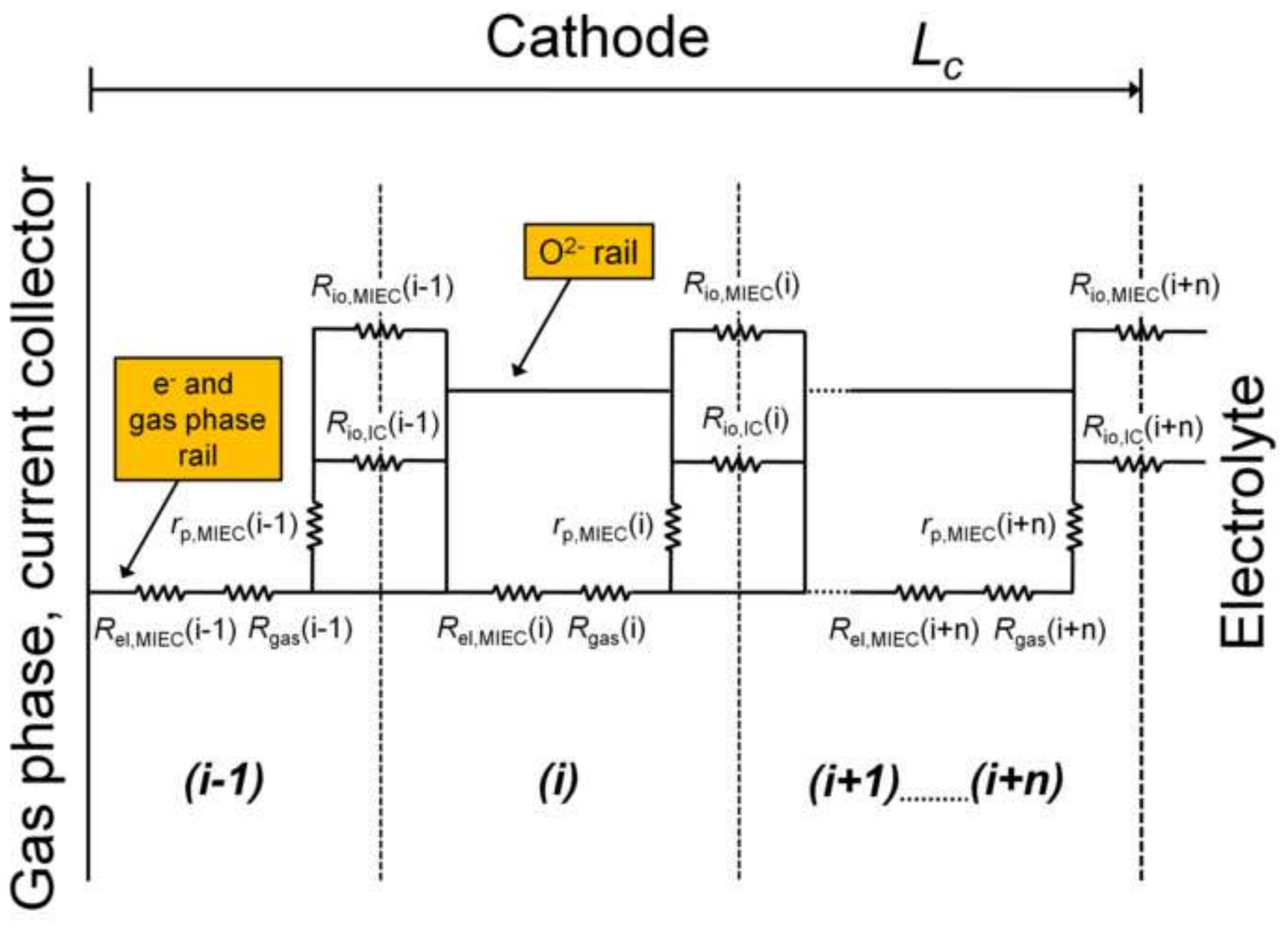


Composition, Microstructural (e.g. thickness, grain diameters), Material properties (e.g, $\sigma)$, Conditions $\left(T, p \mathrm{O}_{2}\right)$,

Set current in electrolyte (10 A m $\mathrm{m}^{-2}$ ), Set cathode segments (100)

Guess overpotential $(\eta)$ at electrode/gas interface $\left(1 \times 10^{-7} \mathrm{~V}\right)$

Obtain $i=\frac{\eta}{r_{p}}$ in all segments while calculating all other parameters (e.g. $P_{i}$, $A_{\text {MIEC }}^{s p}, \sigma_{i}^{e f f}$, etc.). Note that the gas concentration polarization contribution is not included in the calculation.

Vary $\eta$ until the current in the last segment is equal to the set current in the electrolyte

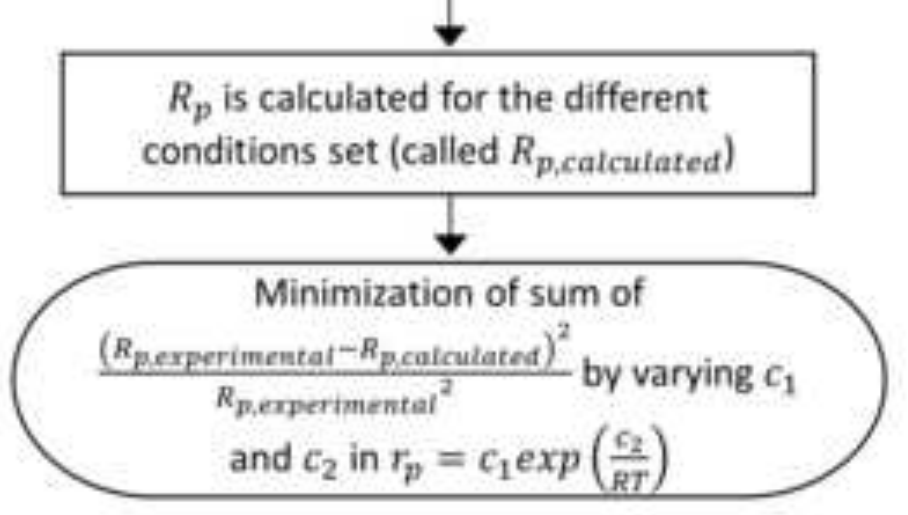


Composition, Microstructural (e.g. thickness, grain diameters), Material properties (e.g. $\sigma)$, Conditions $\left(T, p \mathrm{O}_{2}\right)$.

Set current in electrolyte $\left(10 \mathrm{~A} \mathrm{~m}^{2}\right)$, Set cathode segments (100)

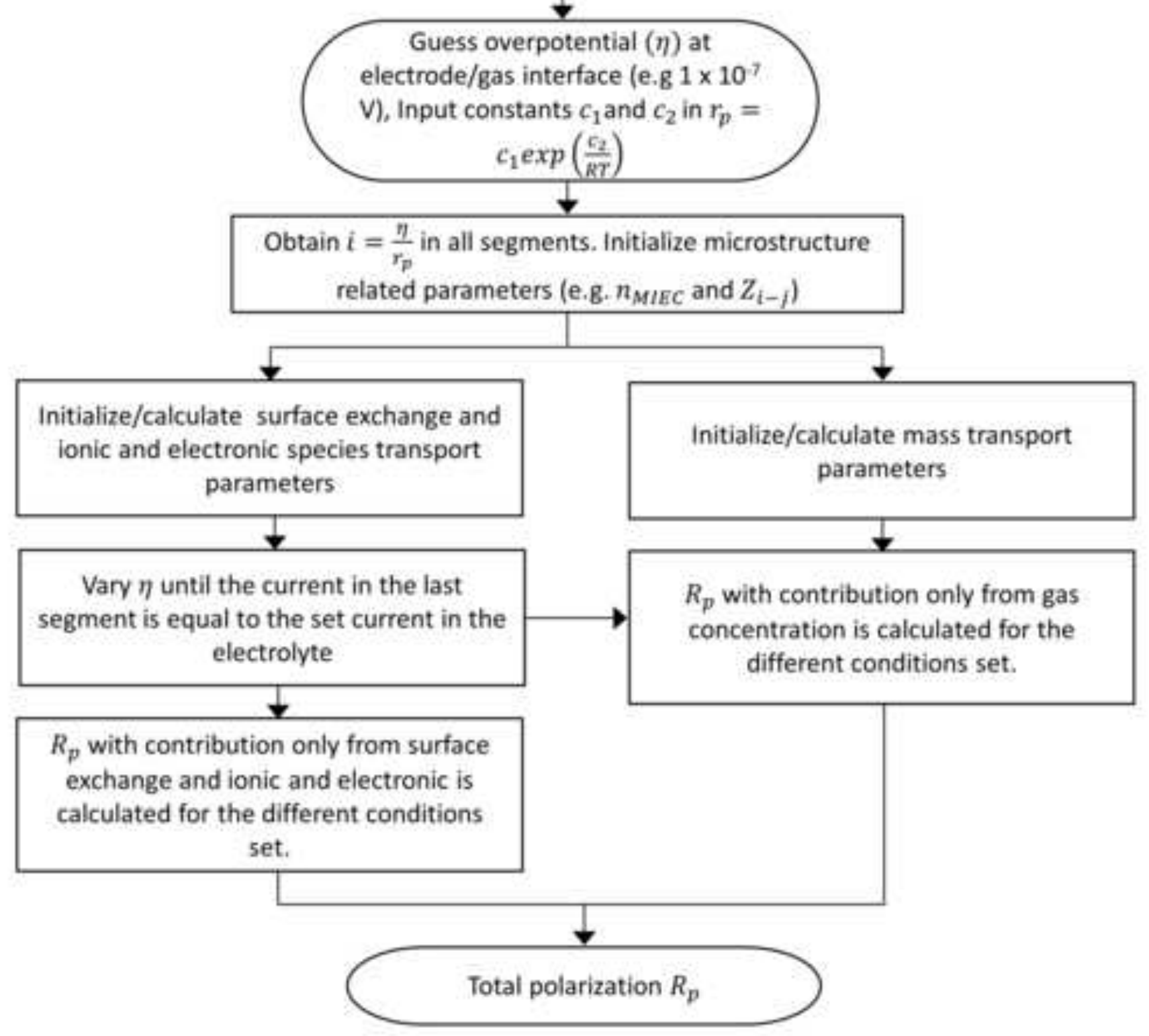


(a)

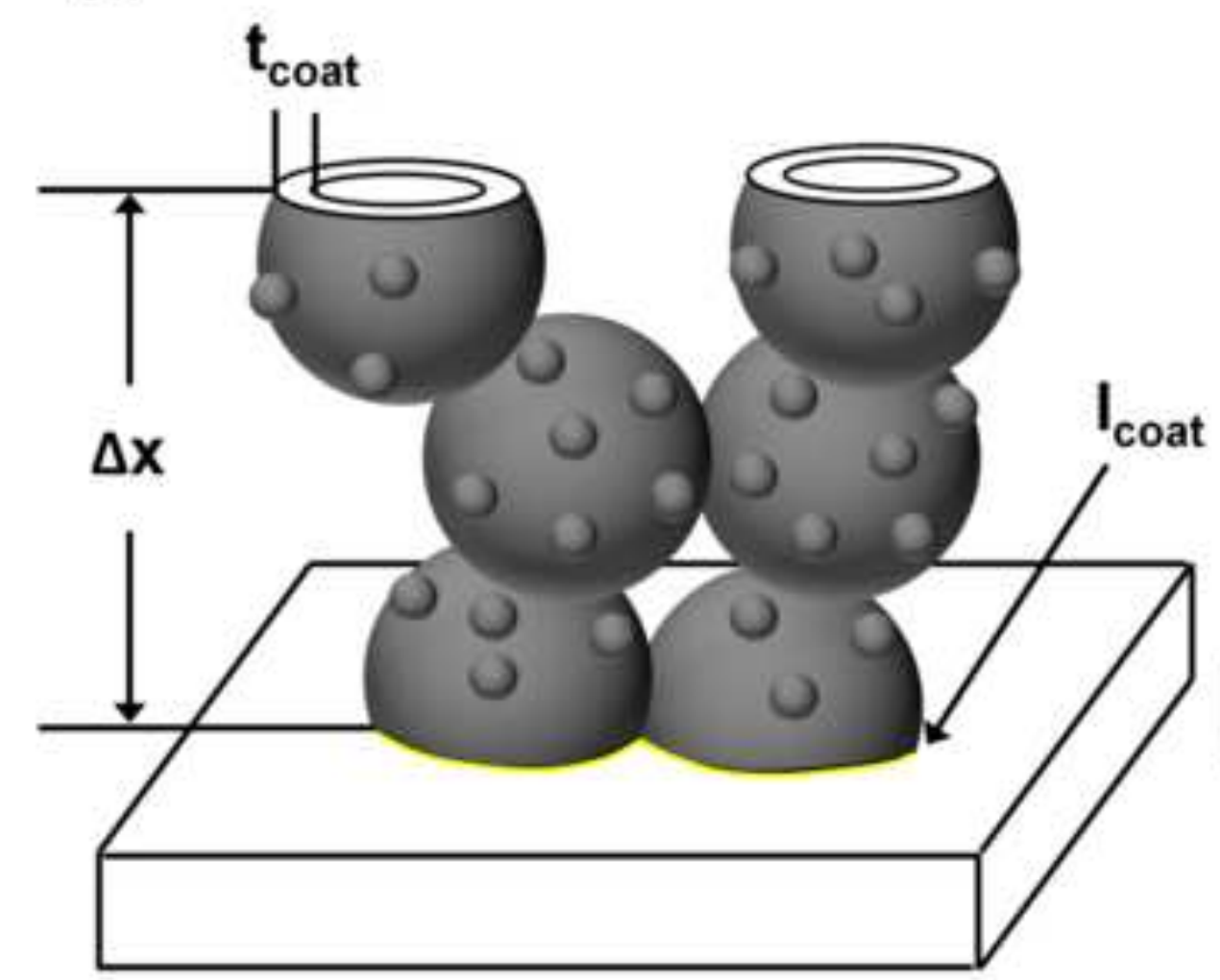

(b)

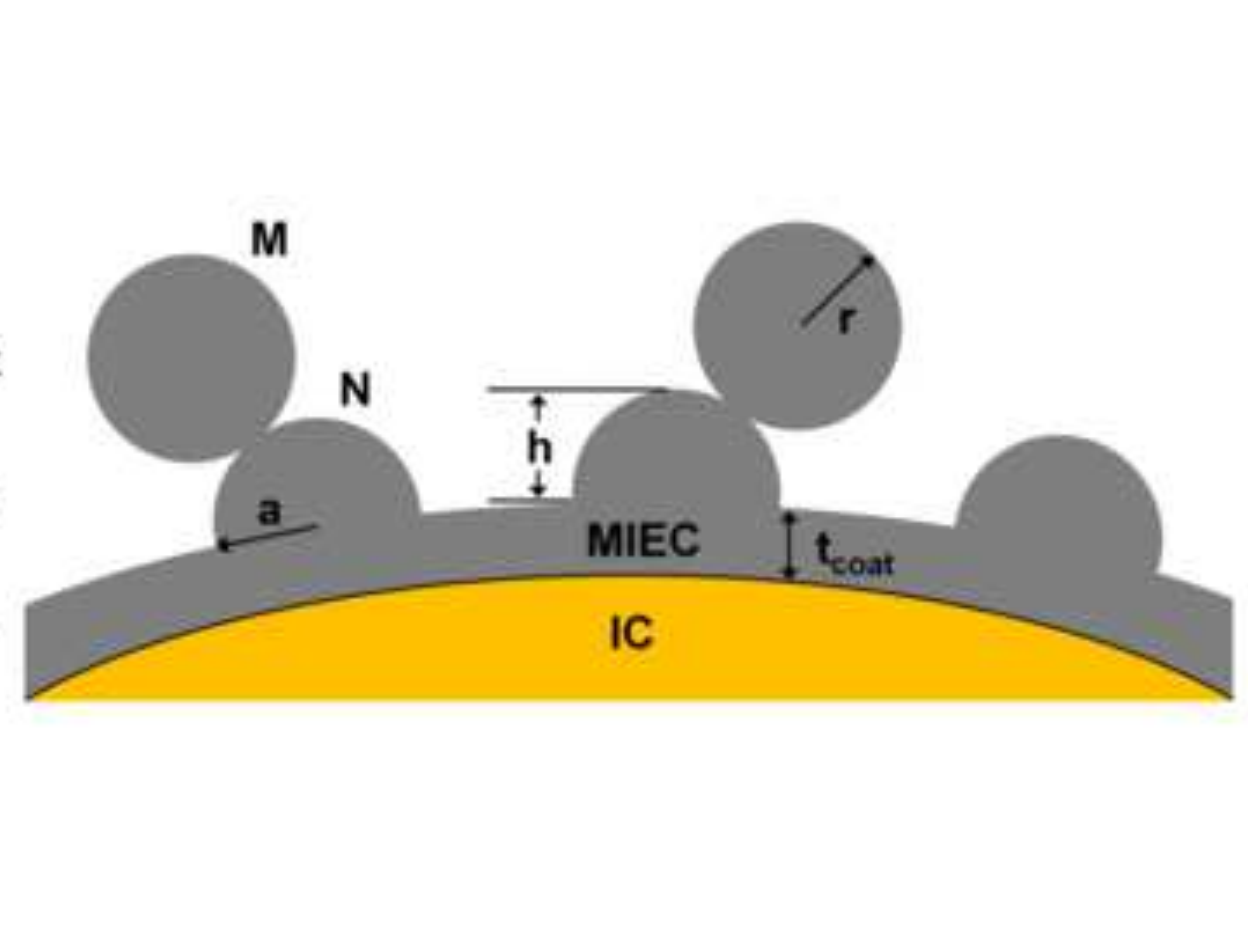




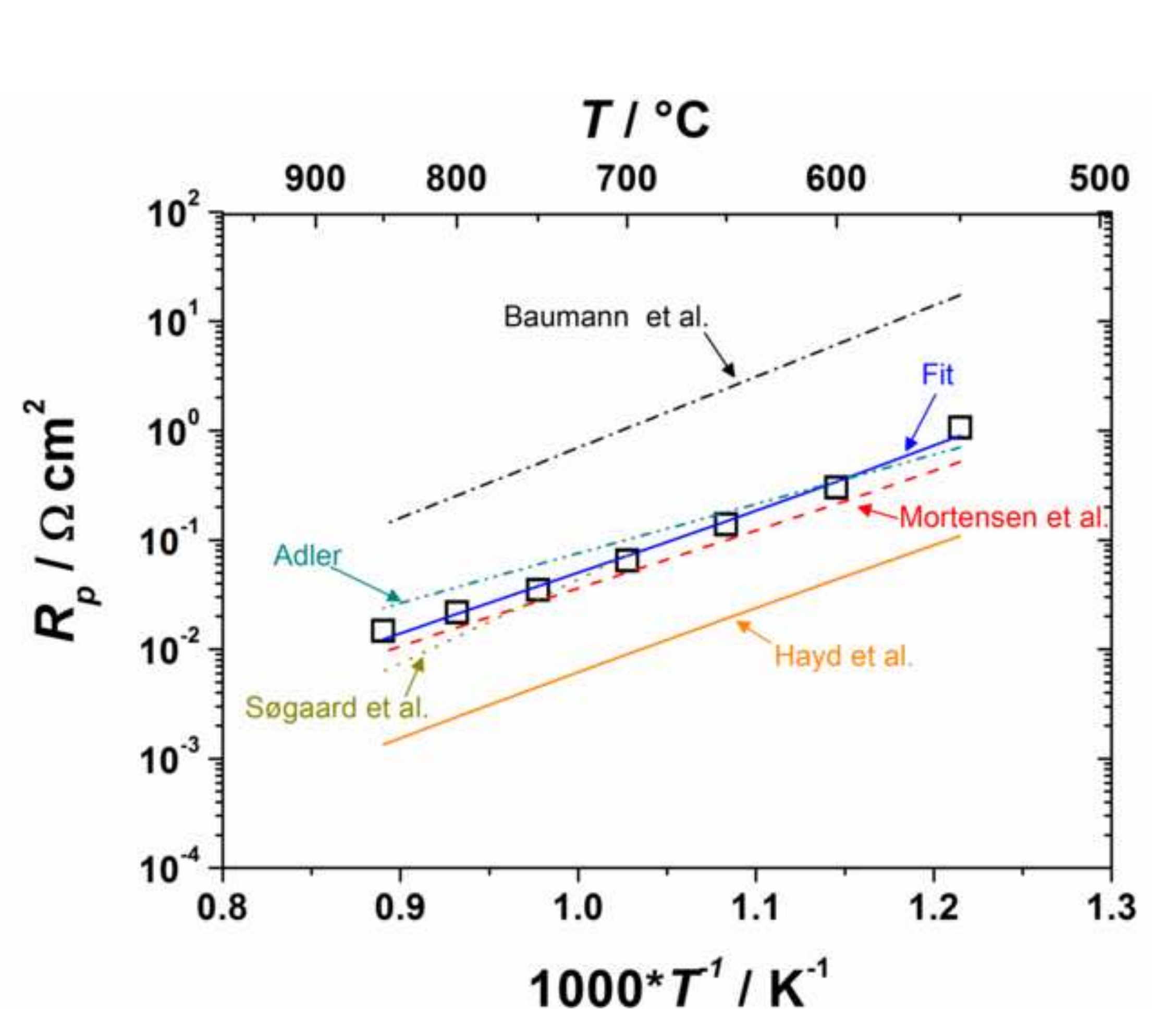

TIOC

(1)




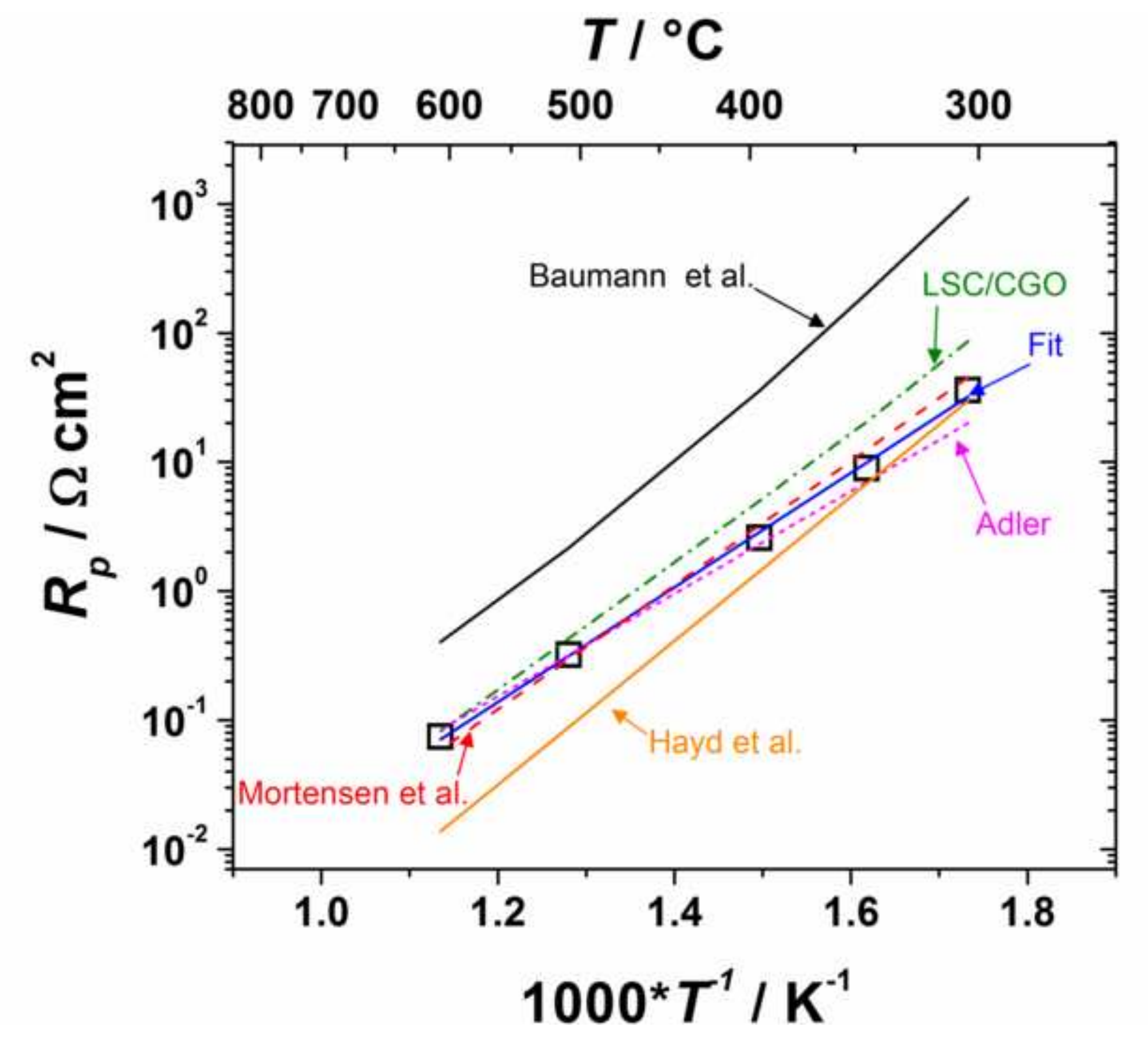

TI $10 \mathrm{C}$ 


\section{$\mathrm{T} /{ }^{\circ} \mathrm{C}$}

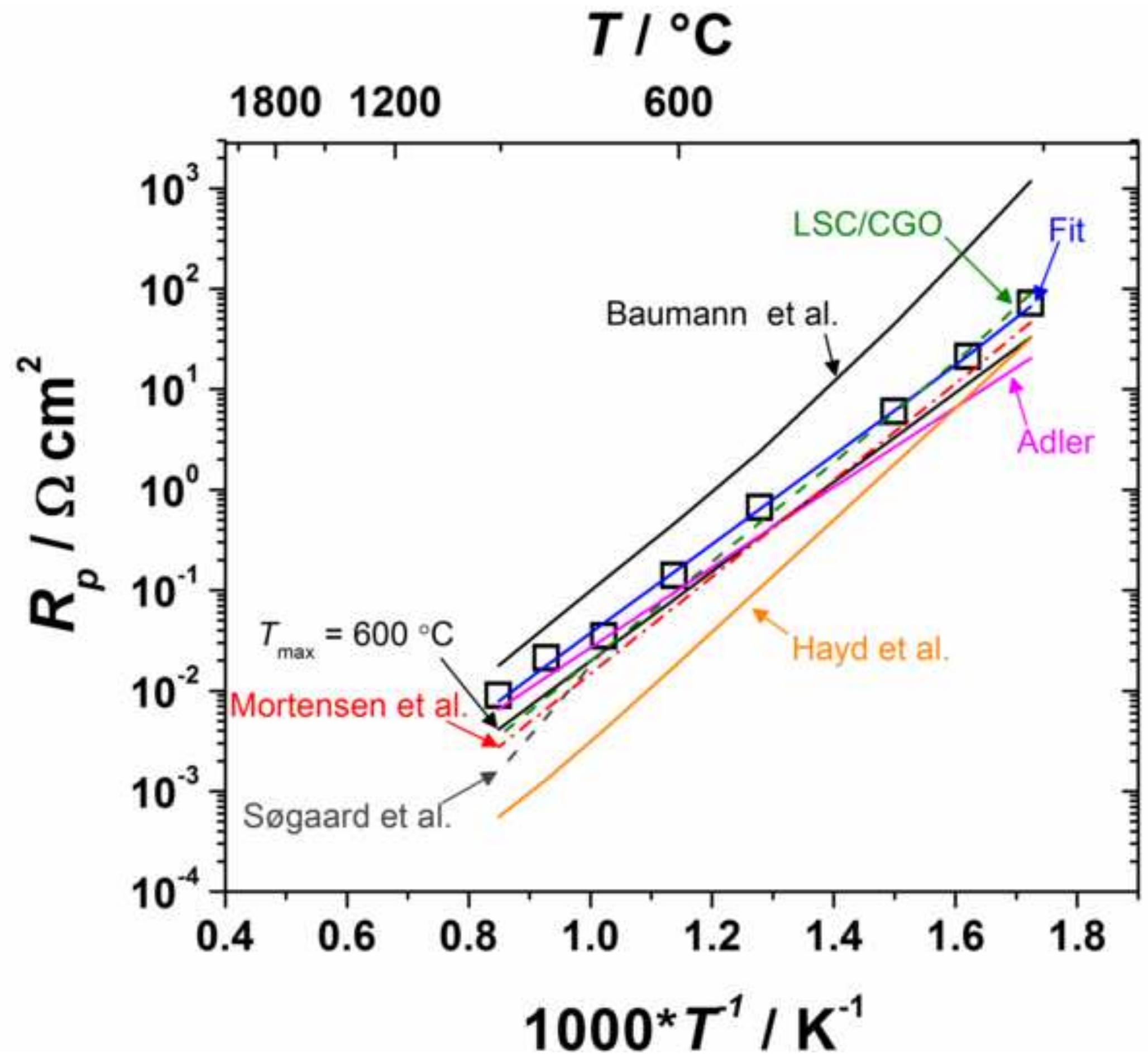


(a)

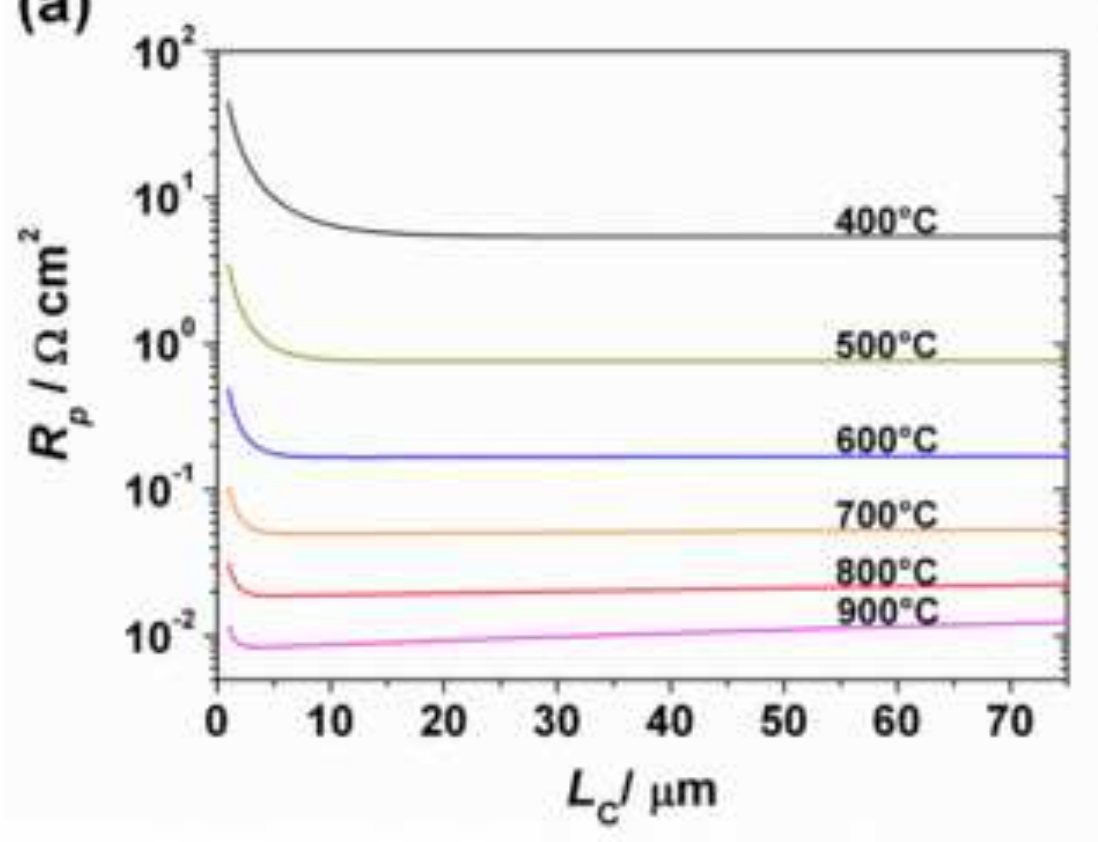

(b)

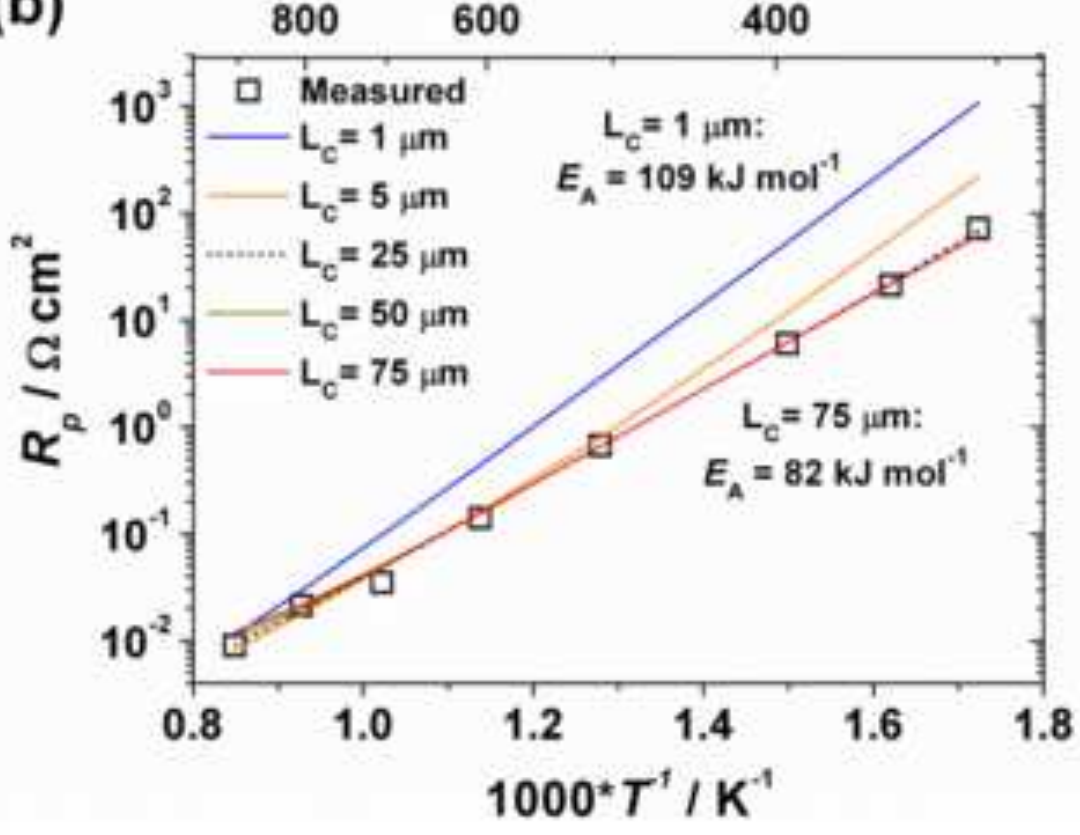

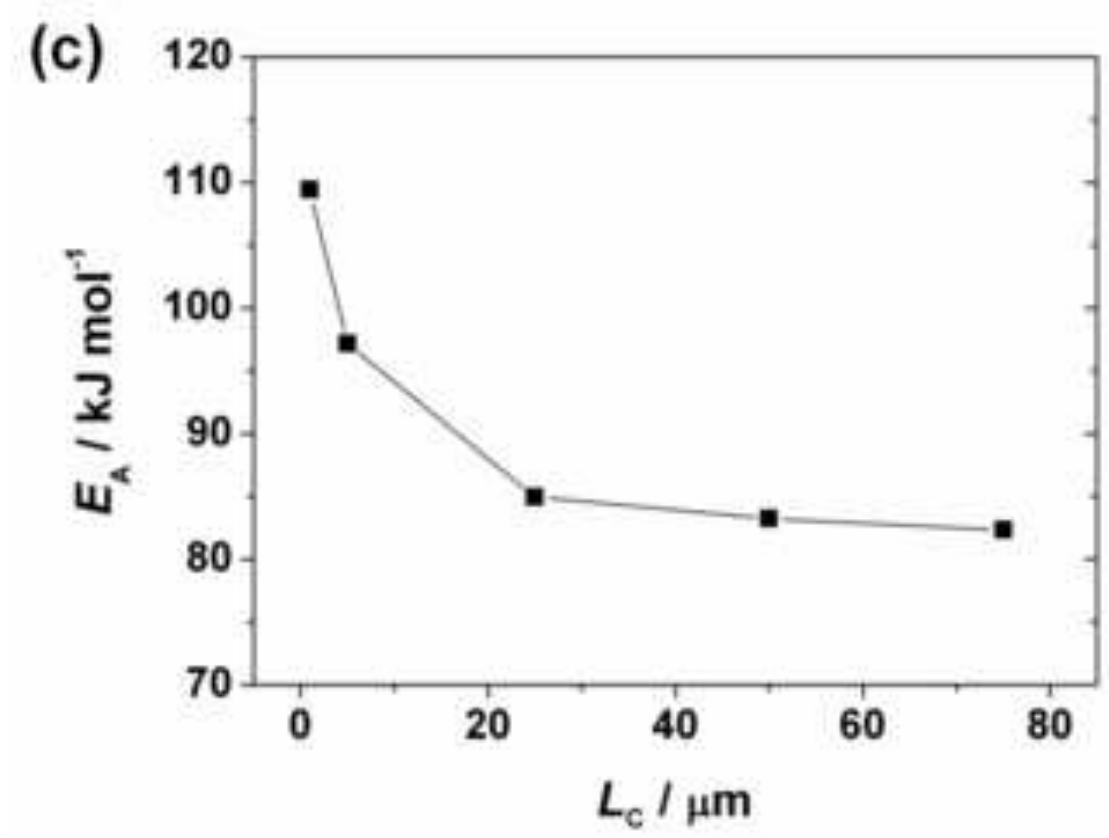



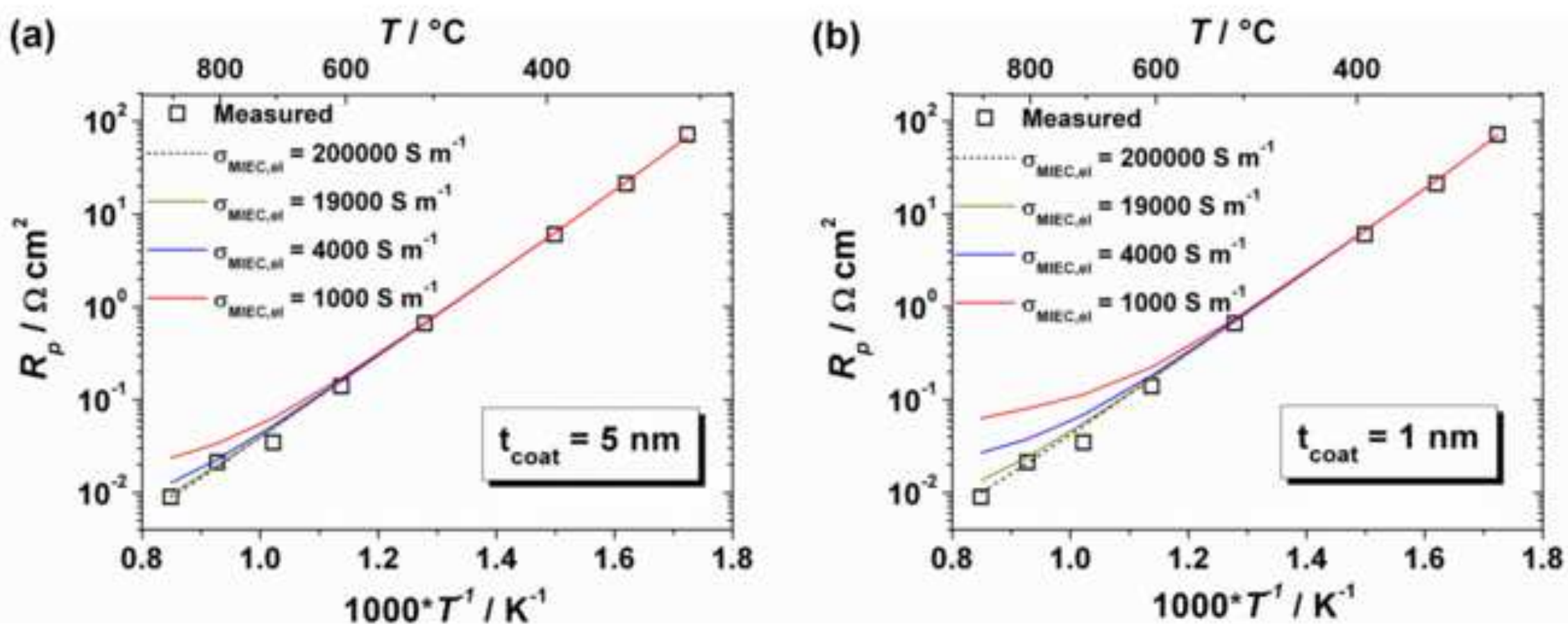
(a)

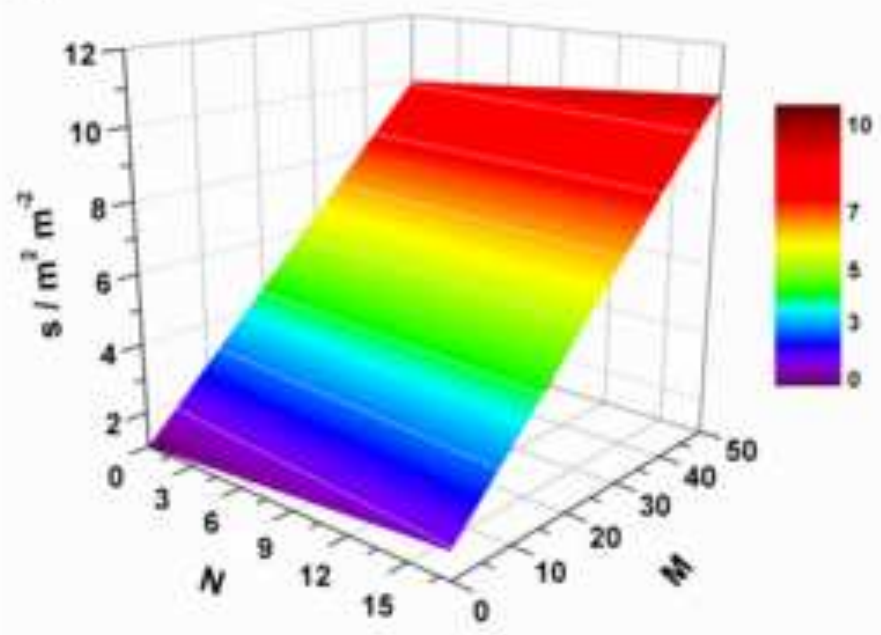

(c)

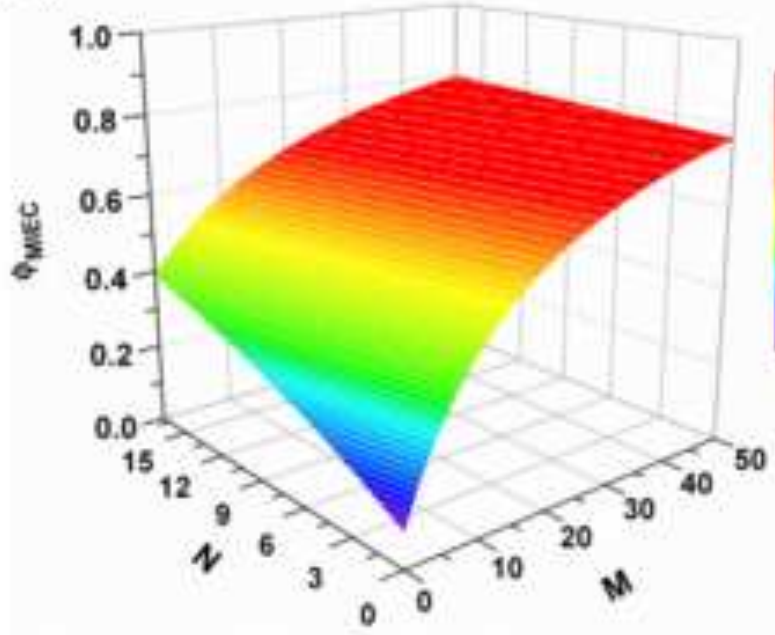

(b)

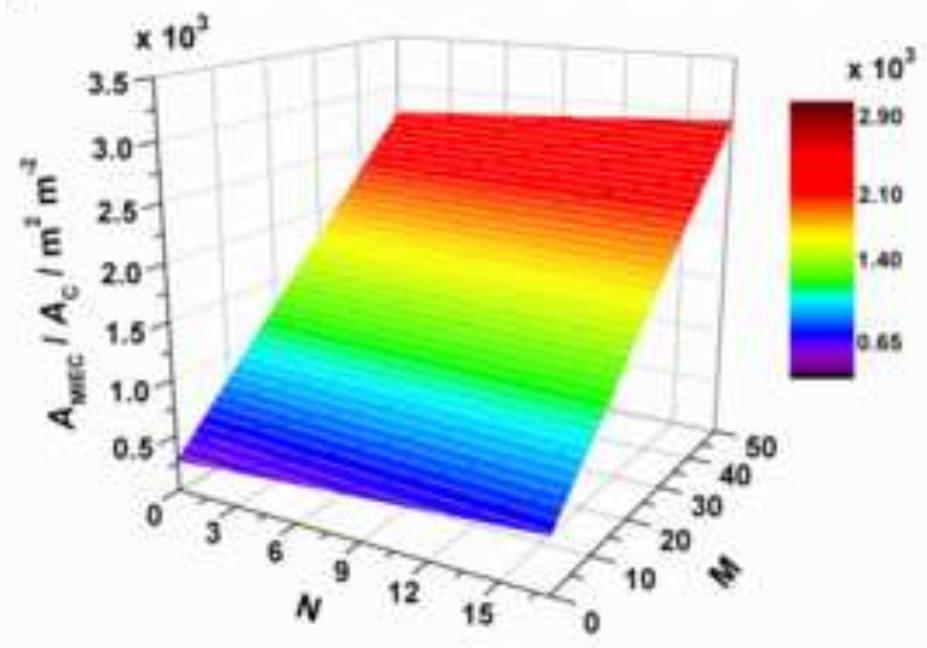

(d)

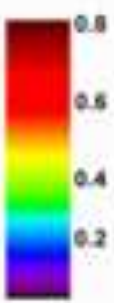

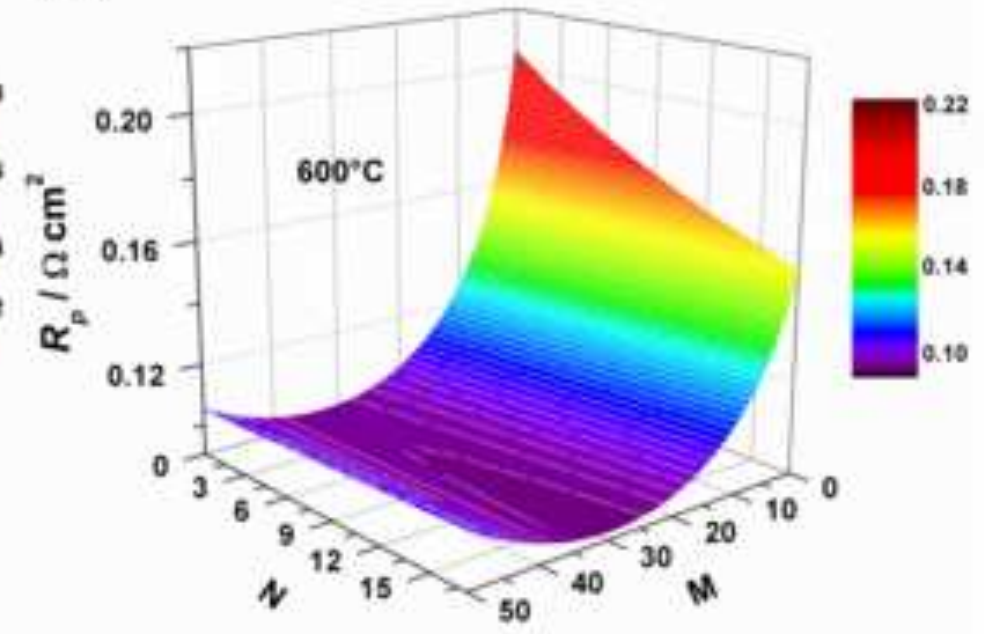


(a)

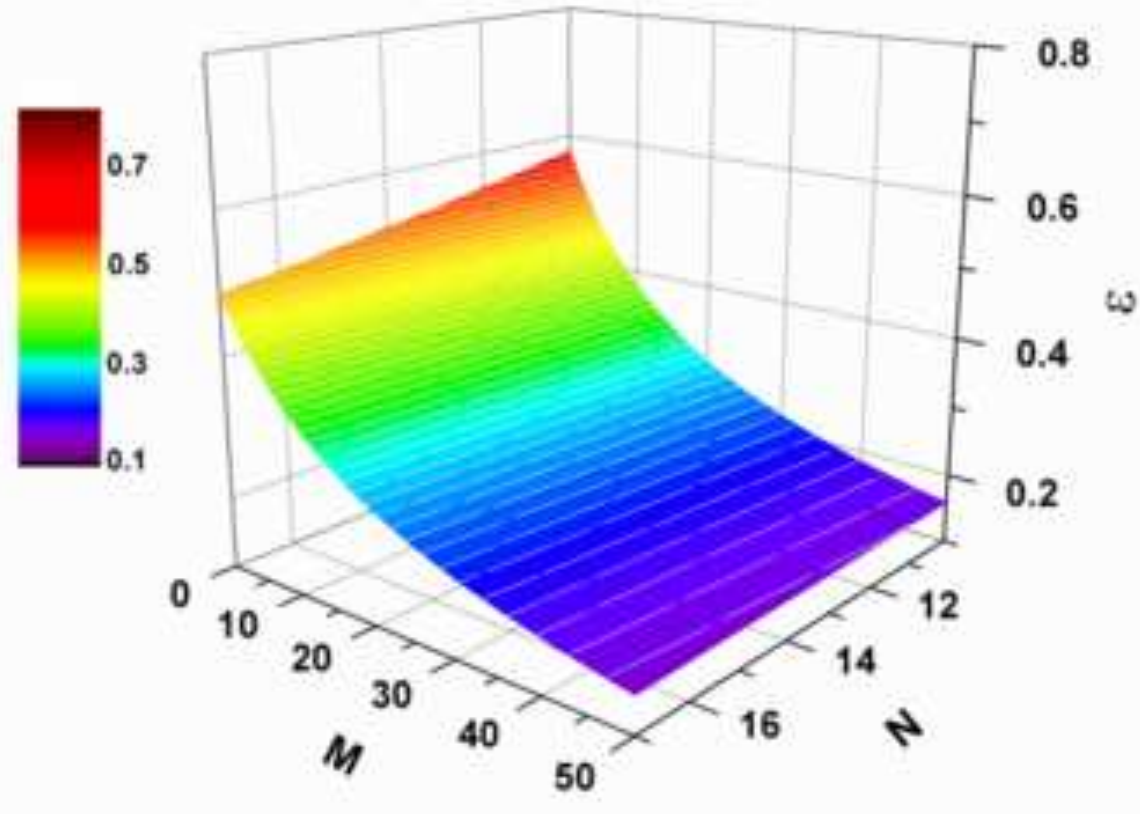

(b)

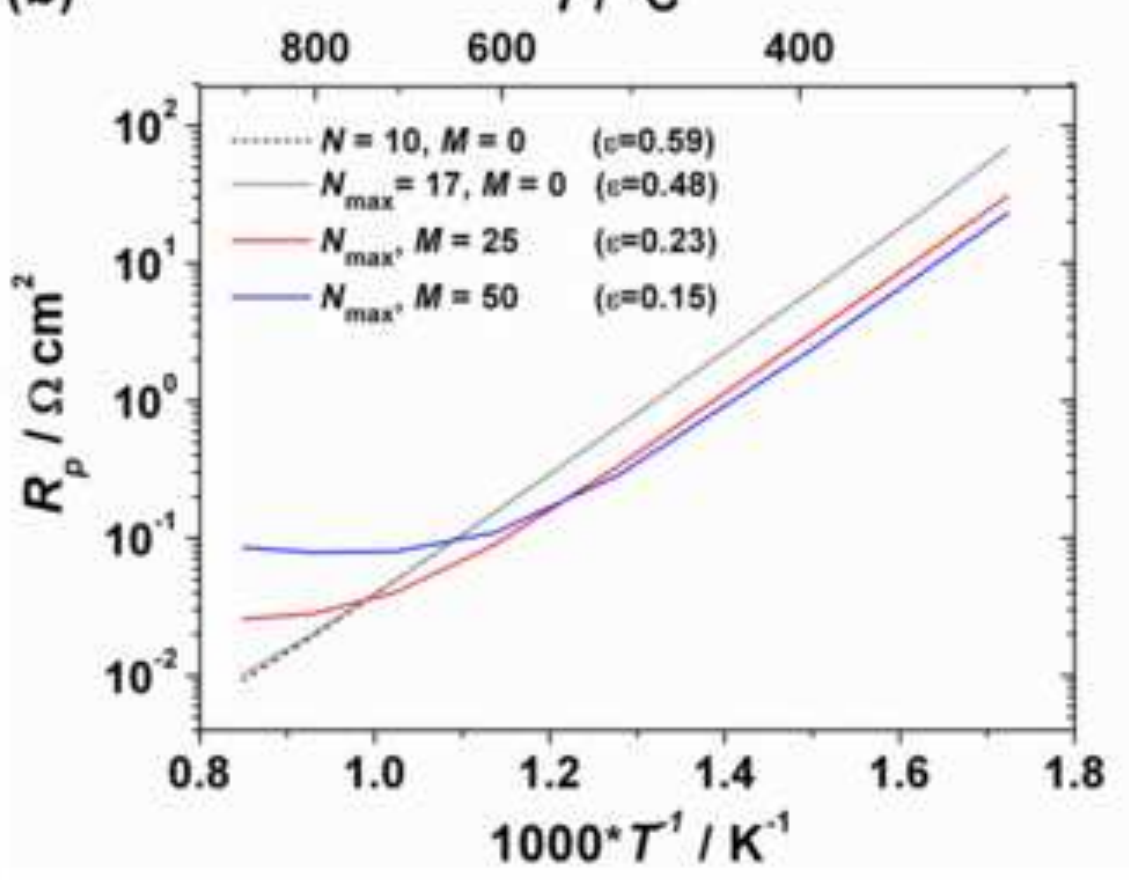




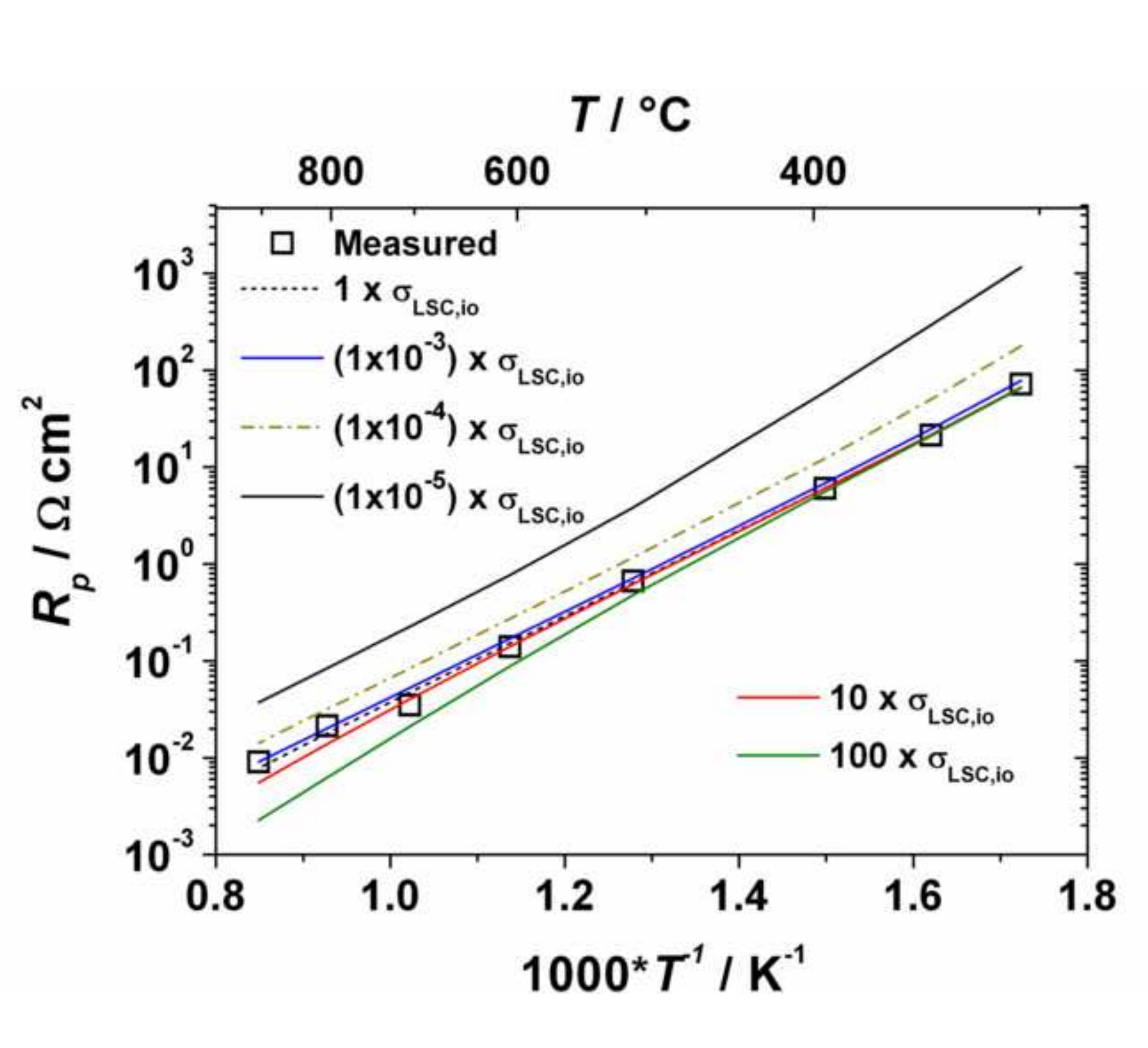

TI ${ }^{\circ} \mathrm{C}$

.

.



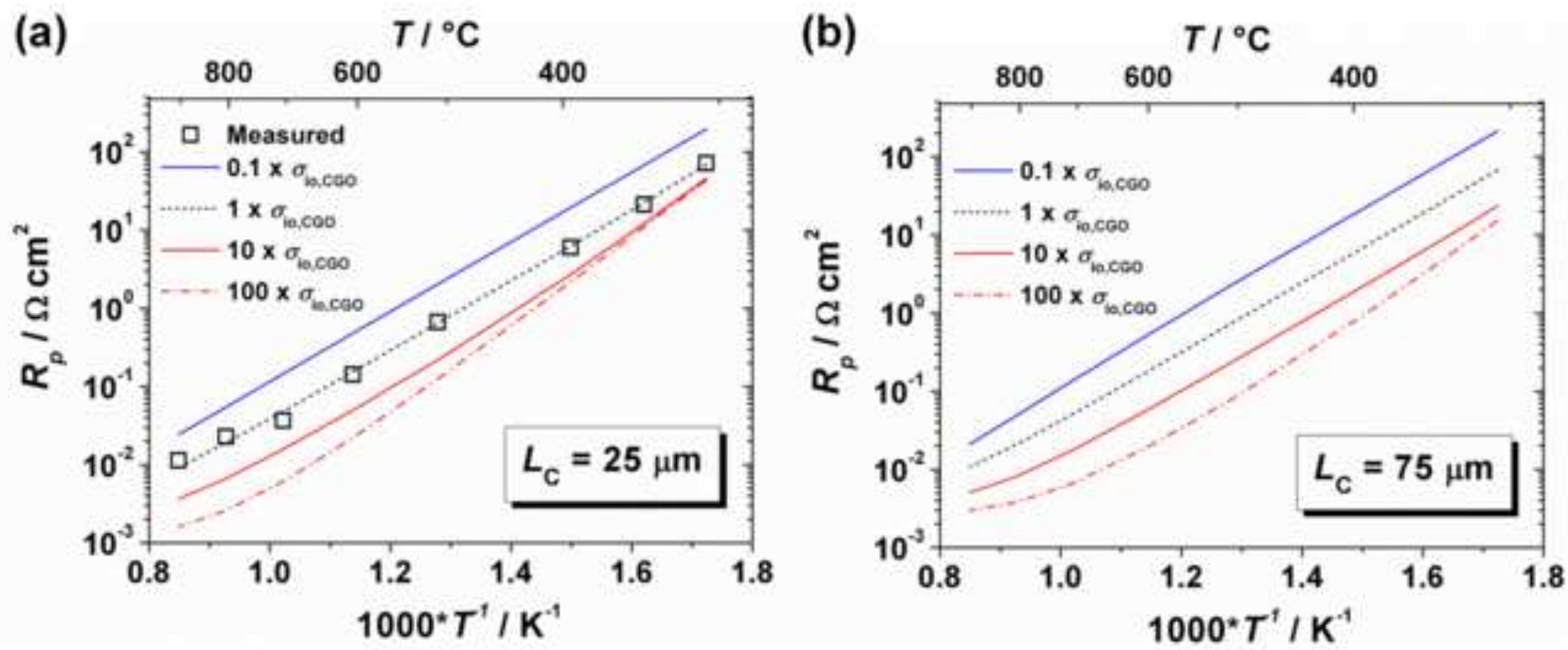

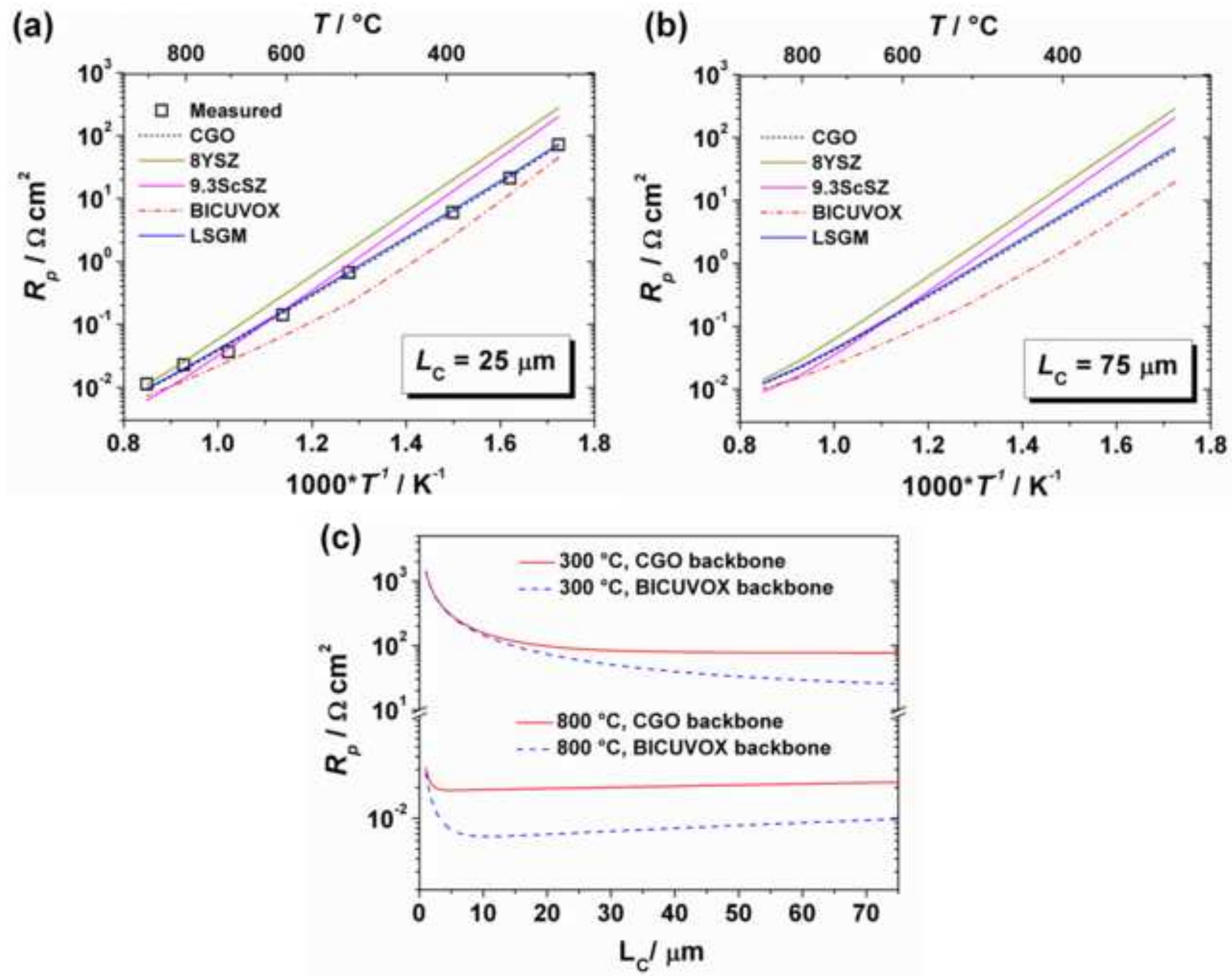

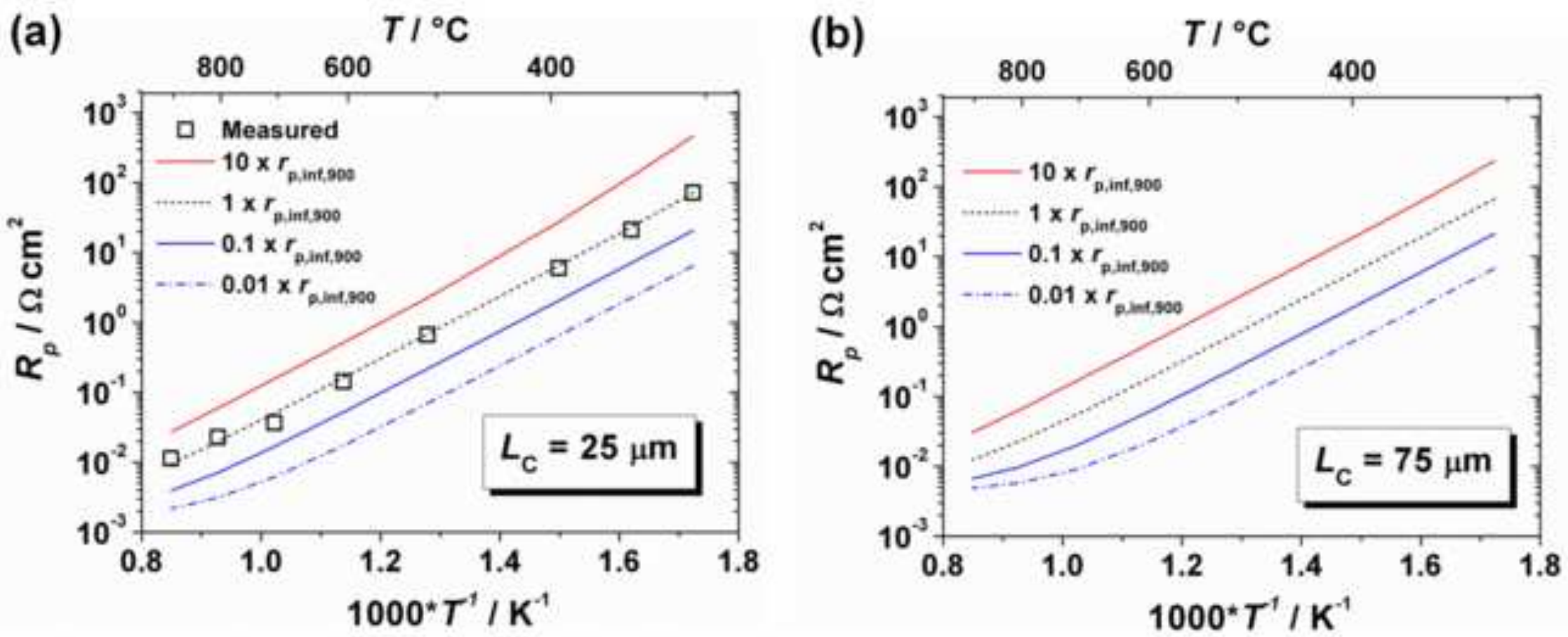


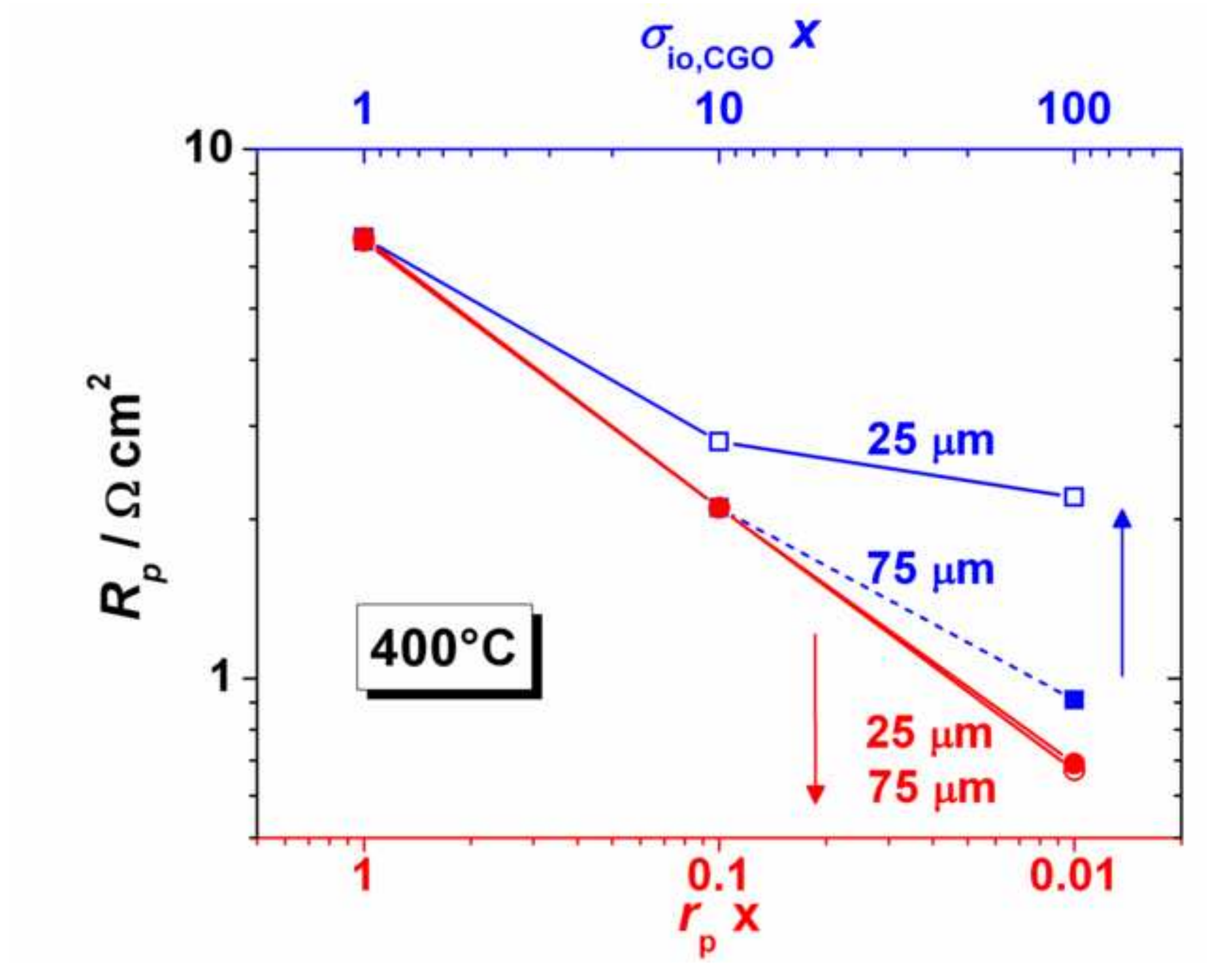

